\title{
A multi-perspective lens on web assurance seals: contrasting vendors' intended and consumers' perceived effects
}

\author{
Julian Löbbers ${ }^{1} \cdot$ Sebastian Lins ${ }^{2}$ (D) $\cdot$ Theresa Kromat $^{2} \cdot$ Alexander Benlian $^{1}$. \\ Ali Sunyaev ${ }^{2}$
}

Published online: 14 May 2020

(c) The Author(s) 2020

\begin{abstract}
Web assurance seals are actions taken by e-commerce vendors to increase their trustworthiness and alleviate consumers' concerns. In their essence, web assurance seals are a product of negotiations, adoptions, and settlements among various groups of interests (e.g., seal authorities, vendors, consumers, or governmental institutions). However, previous research has hitherto used a unilateral research perspective when studying web assurance seals (i.e., either consumer- or vendor-centric), which has acted as a gridlock for web assurance seal literature development. Drawing on signaling theory, we use a ranking-type Delphi study with three distinct, yet mutually supportive expert panels $(N=60)$ to compare vendors' intentions to acquire web assurance seals and perceived effects by consumers. Our results uncover a mismatch between consumers' perceptions and vendors' intentions of web assurance seals, unintended side effects as well as vendors targeting other stakeholders than consumers, ultimately providing starting points for research to move forward.
\end{abstract}

Sebastian Lins

sebastian.lins@kit.edu

Julian Löbbers

loebbers@ise.tu-darmstadt.de

Theresa Kromat

theresa.kromat@kit.edu

Alexander Benlian

benlian@ise.tu-darmstadt.de

Ali Sunyaev

sunyaev@kit.edu

1 Department of Law and Economics, Chair of Information Systems \& E-Services, Technische Universität Darmstadt, Hochschulstr. 1, 64289 Darmstadt, Germany

2 Department of Economics and Management, Institute of Applied Informatics and Formal Description Methods (AIFB), Karlsruhe Institute of Technology (KIT), Kaiserstraße 89, 76133 Karlsruhe, Germany 
Keywords Web assurance seals $\cdot$ Delphi study $\cdot$ Signaling theory $\cdot$ e-commerce

\section{Introduction}

Given the uncertainty of e-commerce transactions (e.g., unauthorized collecting, storing, and transmitting of consumers' data), third-party assessments such as web assurance seals have been considered as an important means for vendors to reduce consumers' concerns regarding privacy, security, or business-integrity [41]. By web assurance seals, we refer to graphical cues embedded in vendors' online websites that independent third-parties grant as proof of endorsement after vendors completed a thorough and voluntary attestation process [52]. Web assurance seals become increasingly relevant for both vendors, as can be seen in the growing adoption rates [2, 16, 43], and consumers having more faith in certified websites [115]. Especially, seals such as 'Certified Privacy' by TrustArc (formerly TRUSTe) or 'Norton Secured' by Symantec have gained much attention among scholars and practitioners alike $[2,96,123]$. Likewise, the major European seal authority TrustedShops has currently issued more than 20,000 web seals to websites to strengthen these websites' trustworthiness [121]. The EU's General Data Protection Regulation (GDPR) directive posits also that voluntary data protection seals will be used as the primary means of signaling compliance with GDPR requirements. A major cause is the inexorable growth of e-commerce as an economic segment and the increase of diversified and related consumer threats. With 2.3 trillion U.S. \$ in sales in 2017, e-commerce is estimated to account for over $17 \%$ of the retail sales worldwide in 2021 [20].

Although web assurance seals' importance increases, selecting appropriate web assurance seals remains challenging because vendors nowadays face a wide variety of web assurance seals that aim to engender trust by assuring data security and protection in electronic markets [60]. While these web assurance seals differ from each other in their key characteristics, such as their content (e.g., proving compliance with security or data protection requirements) or their process (i.e., independent third-party audit or self-assessment by the vendor) [60], vendors are concerned whether acquiring a specific web assurance seal leads to intended effects on consumers, such as increasing consumers' willingness to buy [53, 77]. These concerns are reinforced by studies highlighting inconsistent findings of seal effectiveness [2, $53,60,70,71]$ and revealing that consumers struggle with grasping the meaning of web assurance seals when surfing online [52]. For example, a recent survey shows that only $19 \%$ of respondents knew what web assurance seals for online shops were [116]. Vendors fear a potential mismatch between the web assurance seal effects as intended by vendors when acquiring a specific web assurance seal and as perceived by consumers. Vendors thus worry whether web assurance seals outweigh related expenses (i.e., costs for acquiring and complying with assurance requirements) if vendor's intentions and consumers' perceptions are out of sync.

Prior research has already analyzed vendor's intentions to acquire web assurance seals, such as signaling quality towards consumers [29], and web assurance seals' effects on consumers, including increasing trust and perceived assurance 
[54]. Although embodying valuable contributions, previous research findings limp in addressing the aforementioned imperative of syncing intentions and perceptions as they have applied a lopsided (and hence limited) view on web assurance seals. That is the analysis of web assurance seals from either a consumer (perceptions) or vendor (intentions) perspective only. We argue that research on web assurance seal effectiveness and practical relevance remains questionable as long as vendor intentions and consumer perceptions are out of sync, particularly because the emergence and development of web assurance seals are a result of continuous negotiations, adoptions, and settlements of interests and compromises from different stakeholder groups and perspectives [5]. Hence, using a multi-perspective lens to study the phenomenon of interest is necessary to come up with novel insights about web assurance seals effectiveness and, most importantly, to deepen our understanding of what is perceived by consumers versus what was intended by vendors regarding web assurance seals. As long as a unilateral view is taken to study web assurance seals, our knowledge base will not be advanced as such approaches contradict the inherent nature of web assurance seals. As a result, seal authorities face the risk of developing web assurance seals that are out of sync with vendors' aims and consumers' needs, hence, leading to the refusal of vendors to acquire web assurance seals after all. Therefore, we strive to address this research gap by answering the following research questions (RQ):

RQ1: What are the prevalent vendor intentions to acquire web assurance seals and consumer perceptions of web assurance seals?

RQ2: To what extent do vendor intentions and consumer perceptions match or differ?

We conducted a ranking-type Delphi study using three distinct, yet mutually supportive panels with overall 60 participants, including consumers, vendors, and seal authorities. Incorporating these stakeholders into our study, we were able to create a unique data set enabling us to derive diverse effects of web assurance seals on consumers (i.e., those (outcome) variables that are expected to be influenced by web assurance seals) as well as intentions to acquire and use web assurance seals by vendors (i.e., those intention variables that are expected to be achieved when acquiring web assurance seals). Besides identifying 15 effects that consumers perceive when recognizing web assurance seals and 18 intentions of vendors to acquire web assurance seals, our analysis-guided by signaling theory-uncovered, first, a mismatch between consumers' perceptions and vendors' intentions of web assurance seals. Second, unintended side effects arise (i.e., skepticism of consumers when evaluating web assurance seals) and undermine the effectiveness of web assurance seals. Third, the fact that vendors do not only use web assurance seals to signal, for instance, integrity and therefore increase trustworthiness among consumers but also target other stakeholders such as competitors, legal authorities, or the market in general forestalling stakeholder-specific effectiveness. 
Our research has several theoretical and practical contributions. First, to the best of our knowledge, this is the first study to utilize a multi-perspective investigation on web assurance seals in e-commerce. We not only contribute to research by revealing that the importance of effects and intentions identified in consumer and vendor panels differ but also by determining intentions were no counter-part effect could be identified and vice versa. For example, whereas vendors aim to increase trustworthiness, consumers perceive a far more diverse set of effects. These advancements expand our knowledge to allow for a more differentiated and nuanced analysis of web assurance seal effectiveness. Second, we validate that common vendor intentions of related research streams are applicable in electronic markets and reveal novel intentions that have not been discussed in related literature to date and are specific for electronic markets, such as Signal data protection and Achieve legal conformity. Third, we provide a more nuanced analysis of the effects of web assurance seals on consumers by identifying effects that have been overlooked in previous research (e.g., skepticism or apathy). We also refine our understanding of prevalent effects (i.e., trust, perceived assurance, and purchase intention), enabling us to derive several recommendations for future research on web assurance seals. Finally, construing web assurance seals as informational signals, we propose a starting point to further develop signaling theory by highlighting the emergence of undermining side effects of signals and acknowledging that signals can have multiple receivers at the same time, which calls for a more fine-grained analysis of signal effectiveness in future research.

\section{Theoretical background}

\subsection{Web assurance seals in e-commerce}

A web assurance seal is defined as a graphical cue embedded in vendors' websites that targets consumers and is issued by an independent seal authority if an online vendor's information systems and processes comply with a pre-defined standard, requirement catalog, or regulation [60]. Web assurance seals involve three actors: seal authorities, online vendors, and consumers. Seal authorities are independent, neutral intermediaries between consumers and vendors that provide forms of oversight to deter or punish inappropriate behavior by the online vendor [55]. The oversight covers, among other aspects: assessing vendors' system documentation about security and data protection measures, interviewing vendors' employees, or conducting on-site assessments to attest compliance. If vendors and their systems and processes adhere to specified requirements, the seal authority awards a formal testimonial, and the vendor is then permitted to present the seal in their communications to consumers and outside stakeholders. Consumers may be able to access detailed information on the seal authorities' attestation results and trust-assuring arguments by clicking on the seal.

While already a wide variety of web assurance seals have been proposed, there are three central structural elements of web assurance seals: (1) content (i.e., the assurances made), (2) source (i.e., the issuing and auditing instance), as well as 
(3) process (i.e., the rigor and frequency of the attestation process) [60]. Regarding the content, one generally differentiates three types of seals: addressing (1) privacy, (2) security, and (3) business-integrity concerns of consumers [41]. First, seals addressing consumers' privacy concerns are used to alleviate consumers' perceived risks in terms of, for example, inappropriate usage of personal data [129]. Second, seals addressing consumers' security concerns (e.g., unauthorized access or malicious programs/malware) are used to reassure consumers that an online vendor uses, for example, intrusion detection software, firewalls, or antivirus/anti-spyware [26]. Finally, seals addressing business-integrity concerns are used to guarantee fair business practices and business transactions before, during, and after the transaction (e.g., safeguarding a prompt delivery of goods) [53].

In electronic markets, web assurance seals reduce consumers' perceived risk and assure proper and safe online transactions by verifying and disclosing incorporated protections (either legal protections or technological safeguards) $[63,83]$. Figure 1 illustrates the well-known web assurance seals in the context of electronic markets. With easy access to vendor information, consumers can determine the vendors' qualities and foresee vendor behavior with greater accuracy and confidence [56]. Web assurance seals are particularly relevant for electronic markets because consumers mainly transact with unfamiliar online vendors and thus face a high degree of uncertainty [98, 130]. Consequently, web assurance seals are valued, in particular, by small- and medium-size online vendors because they lack a strong, confidence-building market position and a strong reputation [53, 117].

\subsection{Related research on web assurance seals}

Related research on web assurance seals is ever-increasing throughout the recent decades and can be divided into three major streams: (1) developing, designing and innovating seals and underlying attestation processes, (2) taking a vendor perspective, or (3) taking a consumer perspective. Regarding the former, various research has taken a look on how to develop trustworthy seals (i.e., for cloud services [74]), on understanding seals' structural elements [60] and classifying seal criteria [111], and on how to increase the reliability of seals by performing continuous compliance assessments $[65,66]$, among others. In the following, we will discuss related research taking a vendor and consumer perspective in more detail.

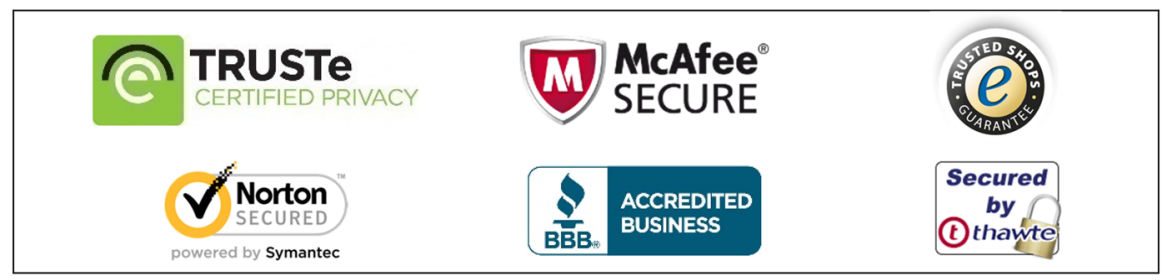

Fig. 1 Example web assurance seals in the context of electronic markets 


\subsubsection{Research taking a vendor perspective}

Research taking a vendor-related perspective analyzes rationales for organizations to acquire web assurance seals and whether organizations can harvest benefits of the acquisition and internalization (Table 1). Researchers do not have a clear consensus regarding the main driving forces behind the acquisition of web assurance seals, in particular, because the acquisition decision is voluntary and not legally required [17, $34,103]$. However, there is a consensus to group those intentions in external and internal factors. Internal intentions refer to when the seal is acquired autonomously, for the organizational benefits that can be derived from its implementation, such as minimization of costs associated with improved internal efficiency. Prior research taking an internal perspective argues that organizations can mature in their implementation of, for example, the ISO 9000 quality management standard underlying the seal by internalizing the actual practices contained in the standard and making

Table 1 Related research taking a vendor perspective

\begin{tabular}{|c|c|c|}
\hline Focus & Main assertions & Example intentions \\
\hline Internal & $\begin{array}{l}\text { Internalize best practices and } \\
\text { standards, underlying web assur- } \\
\text { ance seals, to achieve internal } \\
\text { improvements }\end{array}$ & $\begin{array}{l}\text { Performance } \\
\text { improvements [35, } \\
79,89] \\
\text { Dominant top } \\
\text { management or } \\
\text { employees [6, 44, } \\
69] \\
\text { Realize the com- } \\
\text { pany's strategy for } \\
\text { pursuing quality } \\
\text { [103] } \\
\text { Improve efficiency } \\
\text { and control in the } \\
\text { operations [102] } \\
\text { Achieve cost savings } \\
\text { [17, 69] }\end{array}$ \\
\hline External & $\begin{array}{l}\text { Conform to external pressures } \\
\text { and/or communicate information } \\
\text { about unobservable character- } \\
\text { istics and actions of oneself to } \\
\text { reduce information asymmetry } \\
\text { and consumers' uncertainty }\end{array}$ & $\begin{array}{l}\text { Match competitors' } \\
\text { actions }[17,28] \\
\text { Meet customer } \\
\text { demands }[69,102, \\
103] \\
\text { Comply with govern- } \\
\text { ment policies or } \\
\text { regulations [77, } \\
\text { 102, 108] } \\
\text { Gain a competitive } \\
\text { advantage [28, 35, } \\
\text { 118] } \\
\text { Increase sales and } \\
\text { profit [12, 16, 29, } \\
\text { 44] } \\
\text { Use seals as a } \\
\text { marketing tool [69, } \\
\text { 108] }\end{array}$ \\
\hline
\end{tabular}


changes in organizational quality practices [79]. On the other hand, external intentions refer to the implementation of the seal in response to certain external pressures (e.g., from competitors, consumers, or governments) or incentives such as an enhancement in the image of the organization. Thus, organizations acquire seals to ensure their survival in increasingly competitive markets, rather than to improve performance $[6,15]$. Prior research taking an external perspective proposes that seals may act as a market signal of superior quality and thereby increase sales as well [29, 118].

Given these competing perspectives, prior research is debating whether vendors' intentions of seal acquisitions are more internally or externally driven [17]. For example, the external perspective has been criticized on the basis that organizations are dynamic and active and therefore, they can respond in different ways according to their internal resources and capacities [34]. More importantly, it remains unclear whether these intentions are applicable and relevant in electronic markets because extant research analyzes only seals that are based on ISO standards, like ISO 9001 for quality, ISO 14001 for environmental or ISO 50001 for energy management systems $[34,77]$. In contrast, web assurance seals in electronic markets are considered as a bundle of signals, comprising diverse assurances, such as security, privacy, availability, consumer-friendliness of contracts, and legal compliance [41, 61]. Hence, we are eager to understand vendors' intentions in electronic markets and discuss whether vendors are more internally or externally driven regarding web assurance seal acquisitions.

\subsubsection{Research taking a consumer perspective}

A major research challenge with web assurance seals is to explain how they affect consumers, why these effects occur, and how to predict the effect of a seal on consumers (Table 2). In particular, studies have primarily focused on three effects: (1) trust, (2) purchase intention, and (3) perceived assurance. Trust is defined as consumers' perceptions of a vendor's competence (the ability of the vendor to do what the consumer needs), benevolence (vendor's caring and motivation to act in the consumer's interests), and integrity (vendor's honesty and promise-keeping) [84]. Purchase intention is understood as a predictor for actual purchase behavior [125]. Perceived assurance refers to a consumer's perception of the likelihood that the vendor will try to protect consumer's confidential information collected during transactions and has applied security measures, such as authentication, encryption, and non-repudiation [51].

However, empirical work exhibits inconsistent findings regarding the effectiveness of web assurance seals as our (example) overview in the e-commerce literature reveals (Table 2). On the one hand, studies assert that web assurance seals have a significant positive effect on consumers' trust [41, 81], purchase intention [10, 91], and perceived assurance [54, 128]. On the other hand, scholars could not confirm any positive significance on trust [51, 62], purchase intention [33, 123], and perceived assurance $[73,105]$. These ambiguities proliferated calls for further research on web assurance seals $[2,53,60,71]$. 


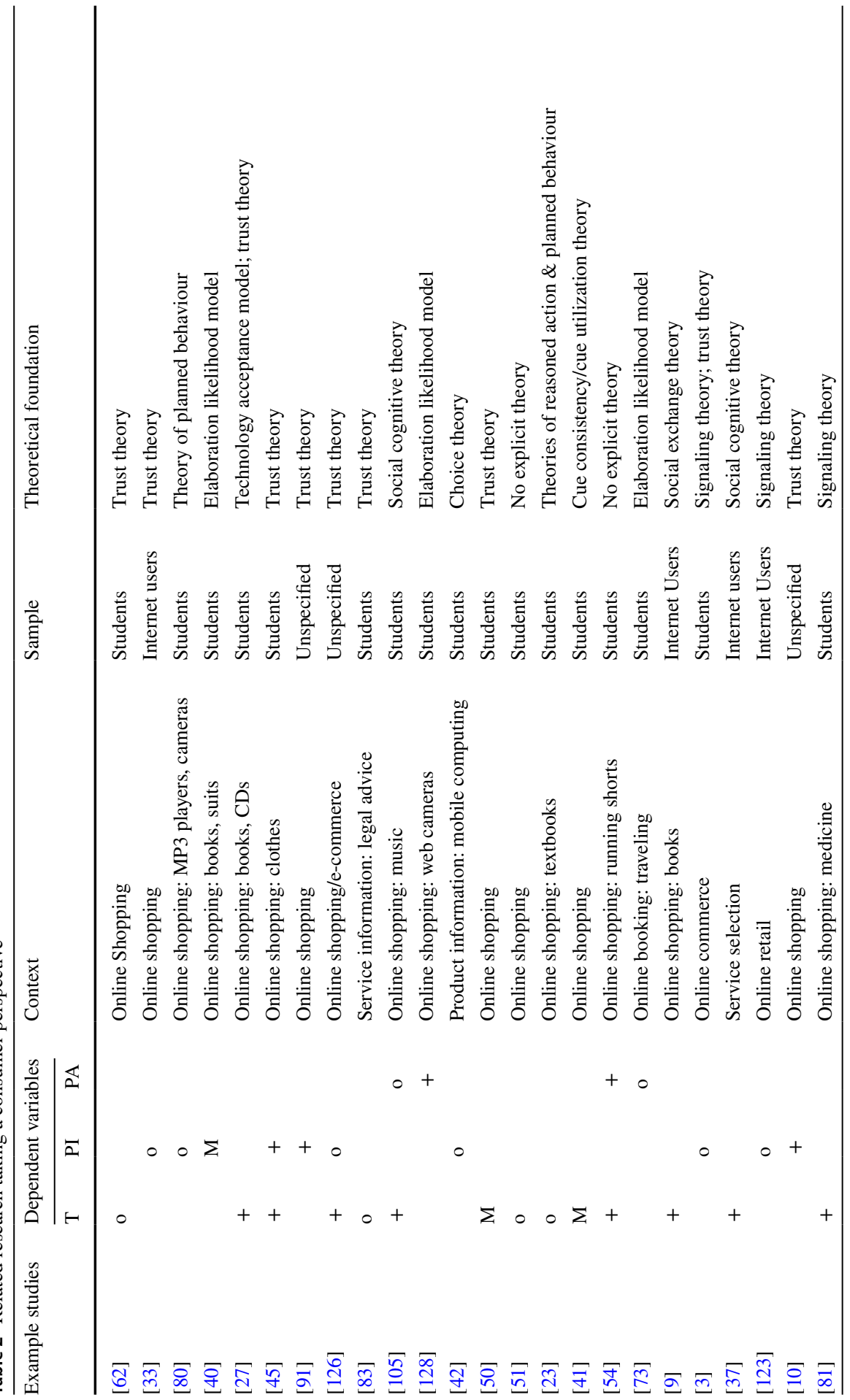




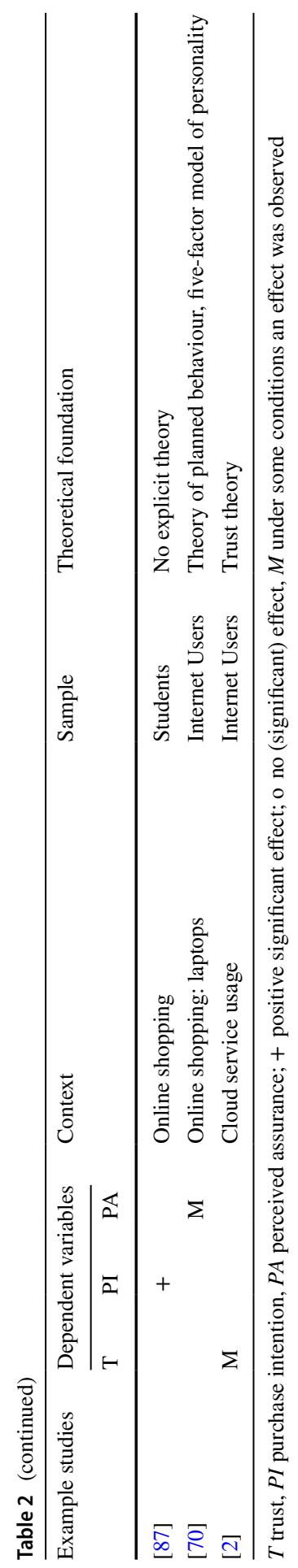


One of the multiple reasons behind the ambiguity of research findings lies in the use of an exclusive set of seal's effects (i.e., what do consumers think and feel when being confronted with seals) and their isolated use in theory building. While only a small number of seal effects has been used in prior research over the last decades (namely trust, purchase intention, and perceived assurance), no solid foundation exists towards why these effects are the most salient to consumers. On the other hand, prior research has already shown that how consumers perceive seals depends on several factors, including perceptual contingency factors (e.g., understanding of seals [73]), contextual contingency factors (e.g., structural elements of seals [60]), and consumer characteristics (e.g., personality [70]). In light of these factors, it is surprising that other effects of seals on consumers have not been analyzed or at least taken into consideration so far. It seems reasonable to assume that consumers' perceptions of and responses to the presence of web assurance seals might be highly diverse as well. When being able to more accurately and comprehensively capture seals' effects on consumers, researchers are empowered to develop a more finegrained theory on seals' effectiveness and increase comparability of results.

\subsection{Signaling theory as theoretical foundation to compare intentions and perceptions}

While embodying valuable contributions, previous research has applied a lopsided (and hence limited) view on web assurance seals by focusing on web assurance seals from either a consumer (perceptions) or vendor (intentions) perspective only. To tackle prevalent issues in related research streams and the lopsided view, we are eager to understand to what extent do vendor intentions and consumer perceptions match or differ. We draw on signaling theory in guiding our scientific course because signaling theory has been recognized to provide strong explanations for the mechanisms of signaling itself as well as on the interplay of the central elements (i.e., signal, signaler, receiver, and signaling environment). Further, it is frequently applied in both web assurance seal research streams: to examine intentions of online vendors to acquire web assurance seals [29, 118], and analyze the value and effects of web assurance seals on consumers $[3,81]$. Because a multi-perspective nature is inherent to signaling theory (i.e., considering the signaler and the receiver as essential building blocks), it provides an appropriate theoretical foundation to explain the mechanisms of web assurance seals and their effectiveness and to compare vendors' intentions and effects on consumers [61, 67].

Signaling theory is fundamentally concerned with reducing information asymmetries between two or more parties (i.e., the consumer and vendor) by performing actions to intentionally communicate positive, imperceptible qualities of a signaler $[30,114]$. At the center of signaling theory is the signaler (e.g., vendor) who possesses the information, which is not accessible to external parties (e.g., consumer or competitors). However, such external parties may find it useful to consider that information when, for example, making a purchase decision. The signal (e.g., web assurance seal) itself is an informational cue that conveys information credibility to the receiver (e.g., a potential consumer) [104]. 
The receiver views and interprets a signal as well as derives inferences from it. Furthermore, the signaling environment affects the entire signaling process. The signaling environment can be distorted when the medium for transmitting the signal inherently reduced the signals' observability or when other receivers of the same signal change the relationship between the original signaler and receiver [11].

From a signaling theory perspective, web assurance seals have to fulfill several requirements to act as reliable signals [7, 61, 67]. First, most web assurance seals are costly and difficult to obtain, and thus, signals might not be easily imitated by low-quality vendors as the disproportional investment may not be justified by future profits. Further, because web assurance seals non-adherence represents a cost to the vendor due to associated penalties, the web assurance seals are themselves a bond against failures (i.e., cases of non-adherence). Second, a vendor that fails to fulfill web assurance seal requirements sacrifices its reputation with current consumers, eliminating any possibility of repeat business and loses other potential consumers due to negative word-of-mouth effects. Third, low-quality vendors are more likely to fail web assurance seal requirements than high-quality vendors. Thus, low-quality vendors will face higher penalty costs and negative word-of-mouth effects for the same web assurance seals than vendors of high quality. Assuming that this cost difference is not compensated by potential gains from cheating (i.e., sending a false/faked web assurance seal signal), high-quality vendors can acquire web assurance seals that low-quality vendors cannot without lowering their profitability. Based on these reasons, web assurance seals can act as reliable signals in consumer-vendor relationships from a signaling theory perspective.

\section{Methodology}

To answer our research questions, we used a ranking-type Delphi approach to first, assess web assurance seals' effects on consumers as well as the intentions of vendors to acquire web assurance seals, and second, to compare the two perspectives. A Delphi study is a systematic and iterative process to anonymously elicit a consensus view from a group of experts [75]. The Delphi method is typically used to understand factors that may influence decision making on a specific issue, topic, or problem using controlled and repeated feedback loops [75]. For the paper at hand, a ranking-type Delphi method is deployed, applying the procedure outlined by Schmidt [110] to brainstorm, select, and rank factors (Fig. 2). We chose the ranking-type Delphi approach (over other approaches such as best-worst scaling) because it enables an iterative and controlled feedback consensus mechanism among a group of experts [14, 46]. Besides allowing to identify web assurance seals' effects on consumers as well as intentions to acquire web assurance seals, this type of Delphi approach also provides insights about the relative importance (or ranking) of these effects and intentions. 


\begin{tabular}{|c|c|c|}
\hline Phase 1 - Brainstorming & Phase 2 -Selection & Phase 3 - Ranking \\
\hline $\begin{array}{l}\text { - Each panelist is asked to } \\
\text { provide at least three artefacts } \\
\text { (either effects or intentions) } \\
\text { - Research team consolidates } \\
\text { artefacts into a two lists } \\
\text { - Panelists receive consolidated } \\
\text { lists and are requested to give } \\
\text { feedback } \\
\text { - Research team revises both } \\
\text { lists based on received } \\
\text { feedback } \\
\text { - In total, } 15 \text { effects and } 18 \\
\text { intentions were identified }\end{array}$ & $\begin{array}{l}\text { - Panelists are tasked to select } \\
\text { the ten most important } \\
\text { effects and ten most } \\
\text { important intentions } \\
\text { - Panelists are asked to justify } \\
\text { their selection (not } \\
\text { mandatory) } \\
\text { - Only those effects and } \\
\text { intentions selected by } \geq 50 \% \\
\text { (effects) and } \geq 45 \% \\
\text { (intentions) are considered } \\
\text { for the ranking phase } \\
\text { As a result, } 11 \text { (consumers) } \\
\text { and ten (seal experts) effects } \\
\text { were selected. Accordingly, } \\
\text { nine (vendors) and eight } \\
\text { (seal experts) intentions were } \\
\text { chosen. }\end{array}$ & $\begin{array}{l}\text { - Each panelist is tasked to } \\
\text { rank the remaining effects } \\
\text { and intentions } \\
\text { - Panelists are asked to justify } \\
\text { their ranking (not mandatory) } \\
\text { - Research team calculates } \\
\text { mean ranking for each item } \\
\text { and level of consensus } \\
\text { - Research team provides } \\
\text { controlled feedback to } \\
\text { panelists } \\
\text { - Panelists iterate their ranking } \\
\text { based on the provided } \\
\text { feedback until adequate level } \\
\text { of consensus is achieved or } \\
\text { predefined stopping criteria } \\
\text { are fulfilled }\end{array}$ \\
\hline
\end{tabular}

Fig. 2 Overview of Delphi phases

\subsection{Panel selection}

We utilized a multi-panel design [14], with each panel designed to obtain unique perspectives on web assurance seals. We used three independent panels for our study to satisfy the multi-perspective nature of web assurance seals: an e-commerce consumer panel (representing consumers' perceived effects of web assurance seals) and a vendor panel consisting of e-commerce experts that operate online shops as a sales channel within their organization (representing the vendors' intentions to acquire web assurance seals). Additionally, we used a panel consisting of experts from independent authorities that issue web assurance seals. These seal authorities not only advise online vendors in weighting seals' intended benefits and costs but they also present and market their web assurance seals to consumers. For example, in Germany, representatives of diverse authorities teamed up in a non-profit board to advise consumers about reliable seals, given the increasing number of fake seals and malicious online vendors. Seal authorities thereby exhibit substantive knowledge about the needs and concerns of both actors: vendors and consumers. Hence, including seal authorities helped us to increase data reliability and validity as well as further substantiate our results with first-hand expert opinions $[14,46]$, who's daily business centers around web assurance seals.

To acquire vendor and seal authority experts, we followed well-known instructions provided for selecting the right experts: we (1) defined minimum selection criteria, such as (a) having knowledge on web assurance seals, (b) having at least 2 years professional experience, (c) having at least one handled/acquired web assurance seal; (2) identified experts that meet the predefined criteria; (3) nominated the chosen experts and asked them to identify further potential participants; (4) ranked experts in priority of invitation based on qualification; and (5) invited experts 
according to established ranking [97]. For the acquisition of the consumer panel, we used a snowball sampling approach, starting with the authors' network.

In general, it is claimed that more experts increase reliability [88]. A large number of experts, however, bears the risk of difficult managing but does not necessarily guarantee better results than the results gained from smaller groups of experts [47]. There is no consensus among researchers regarding the panel size for Delphi studies [4, 14], so that panel sizes can vary from small to large [68]. Against this background, we initially invited 67 panelists ( 21 for the consumer, 20 for the vendor panel, and 26 for the seal authority) of which 60 (21 consumers, 15 vendor experts, and 24 seal authority experts) followed our invitation (response rate: $89.55 \%$ ). Our study had 60 panelists, a number that is at least consistent with other Delphi studies in IS research [14, 46, 48, 113, 119].

Overall, selected seal authority and vendor panelists are considered appropriate experts in case they exhibit good knowledge on web assurance seals and related assessment processes (Table 3), which we measured adapting a three-item construct [24]. To ensure a high-quality panel of consumers, we determined whether subjects have sufficient online shopping experience (Table 3), measured by usage frequency, intensity, and duration [124].

\subsection{Data collection and analysis}

\subsubsection{Brainstorming phase}

We utilized an online survey platform and developed a custom-fit online questionnaire for each of the three Delphi phases. Questionnaires for each phase were pretested with seven academics testing survey functionalities, comprehension, and clarity of questions. Afterward, we sent the survey link to all chosen experts to start the brainstorming phase. To ensure panelists' participation throughout all phases as well as to guarantee high-quality answers, the online questionnaire was constructed as follows: we first introduced each panelist to the generic concept of a Delphi study. Second, we displayed brief information about the study's objectives and context and highlighted the main tasks we were asking the participants to complete. We then asked panelists to answer various questions about potential effects that web assurance seals have on consumers and/or about vendors' intentions to acquire web assurance seals (see the Appendix). Although all questions were deliberately formulated openly, pre-test results (in which we tested a variety of different questions and formulations) seemed to provide promising results.

We highlighted that we are conducting a research project, therefore we requested panelists to respond honestly, and emphasized that answers are kept confidential to decrease social desirability biases when responding. Besides, a major benefit of this questionnaire-based approach is that biases through the influence of other participants are inhibited because questions are answered independently and anonymously using the Internet [95, 97]. To ensure anonymity, yet allow for insightful analysis across Delphi phases, we asked panelists to create an identification label on his/ her own using truncated information about a relative's name and birthday. We also 


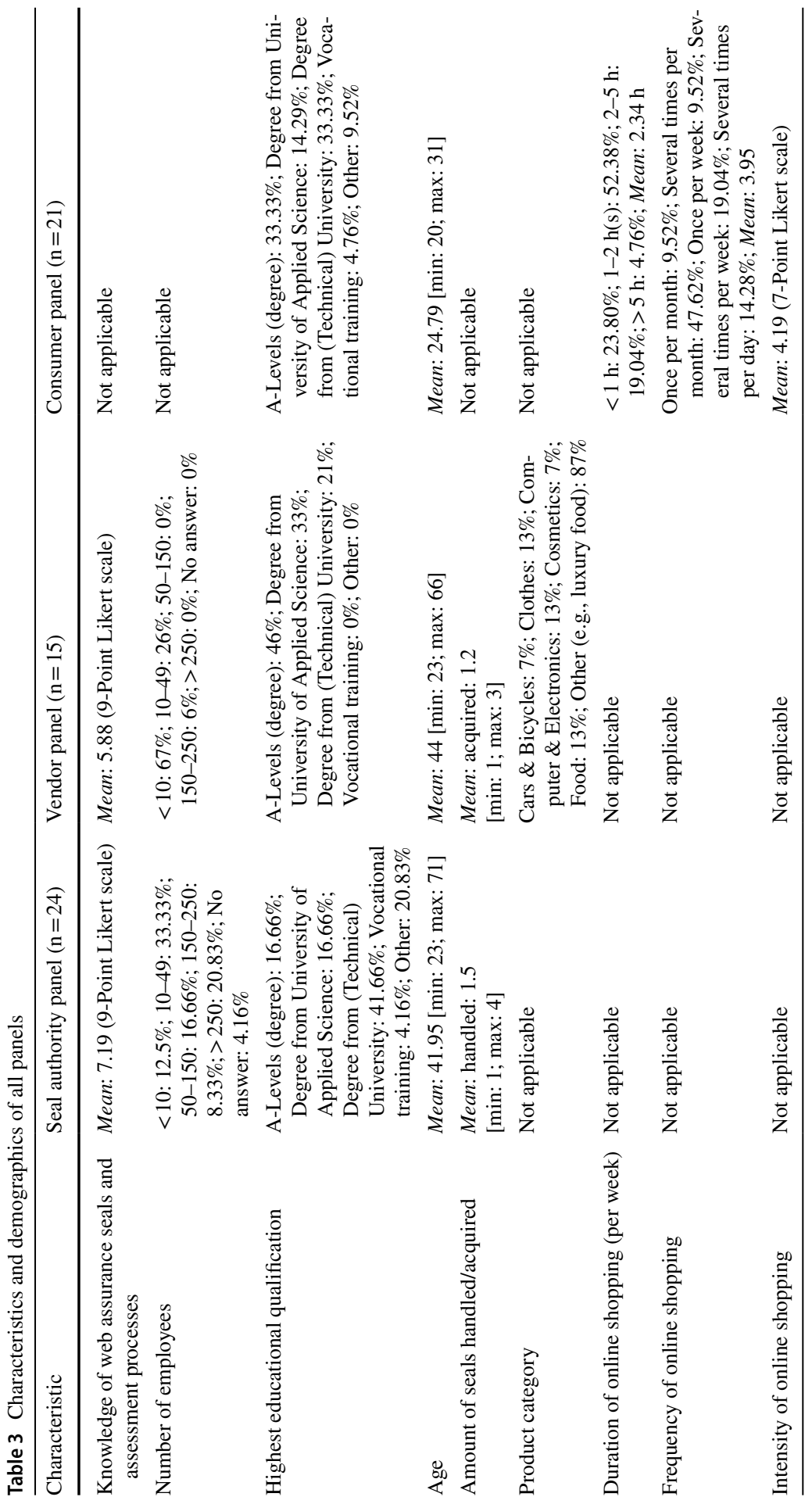


requested online vendors and seal authorities to respond based on their professional experiences and not on their online shopping behavior.

For all questions, we asked for an answer as well as for a short description explaining the given argument or rational. Such descriptions are of great value for clarifying potential answer ambiguities [95]. Except for seven (one consumer, two vendors, and four seal authority experts), all panelists provided at least three answers including descriptions (e.g., not leaving text boxes blank or filled with space characters).

At the end of the brainstorming phase, 60 panelists provided 289 answers regarding web assurance seal effects as well as intentions to acquire web assurance seals. All lists of answers were then consolidated and refined. We aggregated and grouped identical answers and similar ones through content analysis [57]. In particular, we open-coded web assurance seal effects/intentions by analyzing the responses of panelists $[1,13]$. For each answer, we coded a name and a description. If a new effect/ intention fitted to an existing effect/intention, we assigned it accordingly; if otherwise, a new effect or intention was created. During this process, we avoided semantic ambiguities as suggested by Shaw and Gaines [112]. We tried to use the same effects and intentions across all three panels. In case ambiguities occurred regarding the exclusive assignment of a new answer to an existing effect/intention, researchers assigned the new answer to an existing effect/intention according to their best knowledge. Potential coding mistakes would then be corrected during the interim validation phase described in the next paragraph. Four of the authors independently coded the data and compared their results. Following Hayes and Krippendorff [32] suggestions on selecting appropriate inter-coder reliability measures, we calculated Krippendorff's $\alpha$. Compared to other measures (e.g., Scott's Pi), Krippendorff's $\alpha$ has major advantages: it is suitable to calculate agreement between two or more researchers, and it establishes a numerical scale within a continuum of two extremes, which is easily computable [32]. Calculating Krippendorff's $\alpha$ revealed an acceptable level of consensus among researchers $(\alpha=0.805$ for the consumer panel, $\alpha=0.762$ vendor panel, $\alpha=0.834$ for the seal authority panel) [90]. This consolidation process yielded a list of 14 web assurance seal effects and 17 intentions to acquire web assurance seals. It should be noted that we merged effects yielded by consumers and seal authority experts as well as intentions proposed by vendors and seal authority experts, respectively.

In most insightful Delphi studies, at this point, a validation interim phase is induced [100]: the panelists are allowed to revise the outcome of the consolidation and grouping activity conducted by the researchers. The validation of the categorized list of factors has a twofold aim: first, to verify that the stated responses were correctly interpreted and categorized and second, to verify and refine the categorization of factors [95]. After having received the feedback from five consumer panelists, we added an additional effect to the consumer effect list (i.e., Induce interest), resulting in 15 web assurance effects in total. Similarly, feedback given by one vendor resulted in a new intention (i.e., Signal integrity), leading to a final set of 18 intentions. The remaining panelists confirmed the correct coding of their responses.

Further, we applied selective coding to classify effects and intentions under common themes [1, 13], and more importantly, to compare consumers' perceived 
effects and vendors' intentions. Selective coding enables us to create hierarchical classifications that allow moving beyond mere description to a more abstract level of conceptualization [122]. We reflected the identified effects and intentions based on signaling theory principles and related signaling theory literature by applying selective coding. For example, the identified effects Perceive vendor, website, and product quality signal information about unobservable characteristics of the vendor (i.e., hidden information). Likewise, the intentions Signal data protection and integrity aim to communicate information about a vendor's privacy handling (i.e., hidden actions). We, therefore, grouped these effects and intentions into the theoretical category 'convey hidden information and hidden actions'. Overall, and based on the signaling theory, we identified five theoretical categories, which will be discussed in the results section (see also Table 4).

\subsubsection{Selection phase}

In the second Delphi phase, the selection phase, the resulted list from the previous brainstorming phase was randomized and subsequently sent to the panelists 1 week after completion of the first phase and with clear selection instructions. One central aim of this phase is to reduce the list of effects to a manageable size [14, 95]. Literature has proposed various thresholds with regards to the number of items that should be selected within this phase (i.e., between 10 [95] and 20 items [110]). Due to the rather small number of items (15 effects and 18 intentions), we decided to let participants choose exactly 10 . Moreover, we asked for feedback on the selection offering a text box to enter comments. We applied a cut-off threshold greater than $50 \%$ (meaning those effects that were chosen by $50 \%$ or less of the participants were sorted out) for the consumer panel and a 45\%-threshold for the vendor and seal authority panel. It should be noted that we adopted the threshold for the vendor and seal authority panel to provide an equal amount of effects and intentions to be ranked in the respective panels. The selection phase yielded a set of 11 web assurance seal effects chosen by 21 consumer participants and ten web assurance seal effects chosen by 19 seal authority experts. Accordingly, 18 vendor experts chose nine and 19 seal authority experts selected eight intentions to acquire web assurance seals. Because we deemed this a bearable number of items to be ranked (i.e., not too many items), we did not perform a second selection phase.

\subsubsection{Ranking phase}

In the ranking phase, we again transmitted the list of randomized items to the participants to rank them according to their order of importance. This step was performed 1 week after the completion of the second phase. Furthermore, we asked panelists to provide additional feedback elaborating on their importance selection [113]. This not only allowed us to better understand their perspectives but also provided an initial understanding with regards to consensus making within the participating group. To determine the rank of web assurance seal effects as well as acquisition intentions, we used Friedman's Test [25]. As done by other authors from the IS discipline $[14,100,113]$, we calculated Kendall's coefficient of concordance $(W)$ to measure 


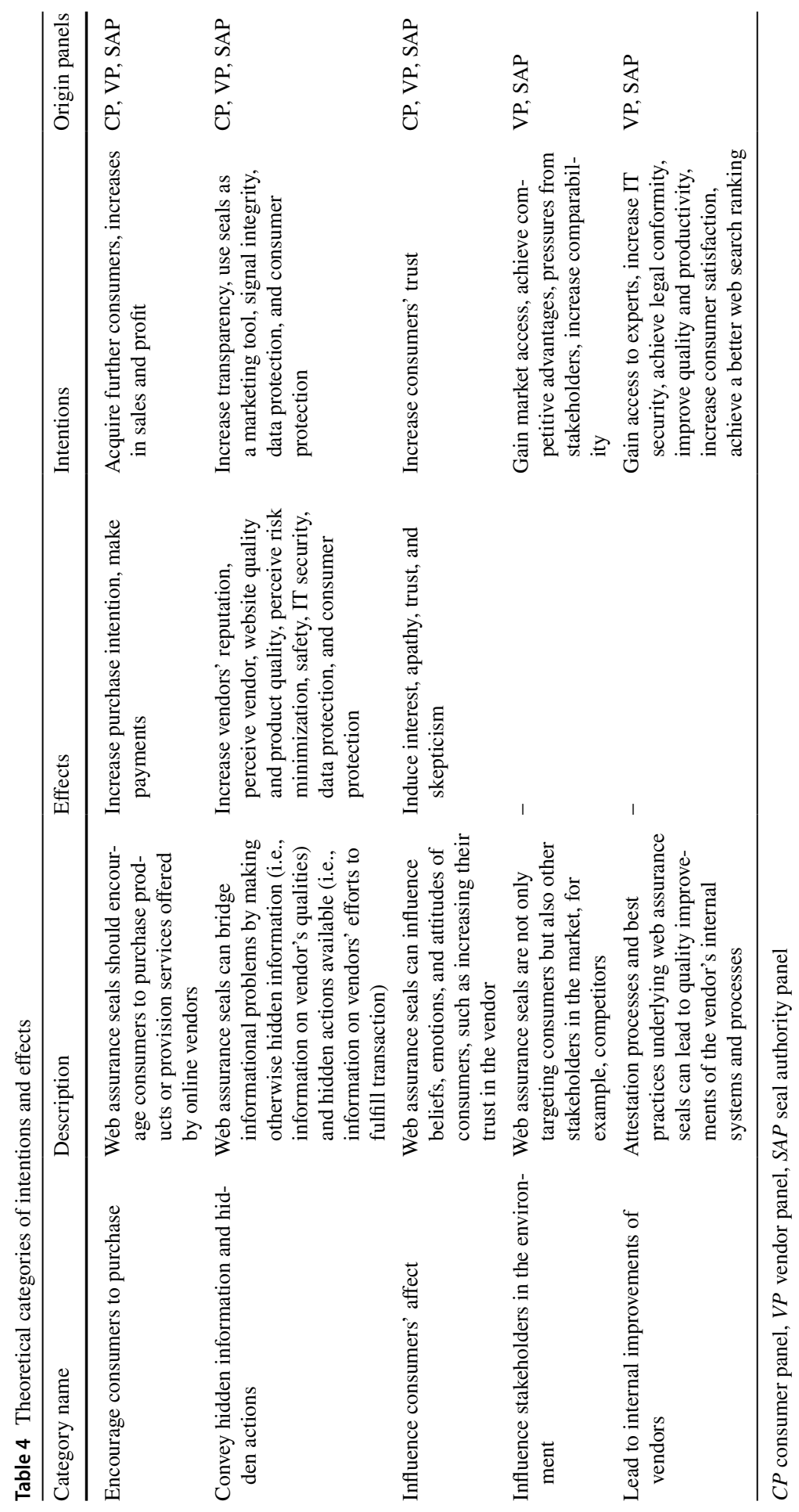


the degree of consensus. While the values of Kendall's $W$ range from 0 (indicating low consensus) to 1 (indicating high consensus), consensus levels are considered weak at $W \leq 0.5$, moderate at $0.5<W \leq 0.7$, and strong at $W>0.7$ [97]. Scholars [97, 113] suggest to reiterate the raking phase until at least a moderate consensus level $(W>0.5)$ is reached. However, according to Schmidt [110], the statistical (in-)significance of Kendall's $W$ does not suffice as a stopping criterion. Therefore, after each round of the ranking phase, researchers should examine and balance the trade-off between feasibility and potential gains from another round [110]. After the first ranking phase, participants only reached a low level of consensus. Web assurance seal effects from consumer panel: $W=0.276 ; N=21 ; \chi^{2}=57.93 ; p<0.001$; web assurance seal effects from seal authority panel: $W=0.358 ; N=12 ; \chi^{2}=37.56 ; p<0.001$; as well as intentions to acquire web assurance seals from vendor panel: $W=0.240$; $N=14 ; \chi^{2}=26.93 ; p<0.01$; and from the seal authority panel: $W=0.193 ; N=11$; $\chi^{2}=14.87 ; p<0.05$. Due to this low level of consensus among the panelists, we conducted a second iteration of the ranking phase 4 weeks after the first ranking phase. We intentionally increased the time between the two ranking phases because panelists already expressed their concerns about participating in an additional ranking phase. However, after the second round, Kendall's $W$ was increased to a moderate level of consensus $\left(W=0.510 ; N=14 ; \chi^{2}=71.39 ; p<0.001\right)$ among consumers and a high level of consensus $\left(W=0.753 ; N=5 ; \chi^{2}=33.87 ; p<0.001\right)$ among seal authority experts regarding web assurance seal effects. Further, vendor experts reached a high level of consensus concerning intentions to acquire web assurance seals $\left(W=0.765 ; N=6 ; \chi^{2}=36.31 ; p<0.001\right)$, while seal authority experts increased consensus in this regard to a moderate level $\left(W=0.659 ; N=5 ; \chi^{2}=23.06 ; p<0.01\right)$.

In this second iteration of the ranking phase, we provided the panelists with various information: (1) the mean rank of each item, (2) the panelists' ranking for each item of the previous iteration, (3) the current level of consensus, and (4) comments indicating why the other panelists ranked the item as they did [95]. The provision of such feedback supports the panelists reaching a higher consensus more quickly [107]. However, due to the increasing drop-out rates and the fact that a moderate to a high level of consensus was reached [97, 113] across all panels, we refrained from conducting a third-ranking phase.

\section{Comparing vendors' intentions and consumers' perceptions}

Overall, study findings revealed 15 web assurance seal effects on consumers as well as 18 intentions for vendors to acquire web assurance seals, which will be discussed next. Outcomes are theoretically grouped into five categories based on the underlying concepts of signaling theory to increase generalizability and theoretical contribution (Table 4). 


\subsection{Web assurance seals aim to encourage consumers to purchase}

In line with signaling theory, for a signal (i.e., web assurance seal) to be effective, the signaler (i.e., vendor) is expected to benefit from some action (i.e., purchasing products or services) performed by the receiver (i.e., consumer) that the receiver would not have done without perceiving the signal [11]. We discovered that vendors gravitate to Acquire further consumers through embedment of web assurance seals on their website. The web assurance seal should persuade consumers to buy online because vendors proved their quality with the issuance of the seal. As one vendor stated, "With the seal, we hope to convince consumers to buy from us". Consumers agree that web assurance seals Increase purchase intention because web assurance seals attest that an independent third-party (i.e., the seal authority) has proven the integrity of the online shop. As a consequence, vendors indicated that they expect Increases in sales and profit following the seal acquisition. Finally, it was revealed that consumers feel that payment transactions with online shops having web assurance seals are more secure than with online shops without seals: "When transacting with certified online shops, I am more willing to use a certain payment method over another". They stated that with certified online shops they are more willing to use riskier options (e.g., credit cards) to handle payments. Thus, web assurance seals can indirectly impact consumers to Make Payments.

\subsection{Web assurance seals aim to convey hidden information and hidden actions}

According to web assurance seal and signaling literature, signals can bridge informational problems [7] by making otherwise hidden information [81] and hidden actions [101] available. While hidden information is outlined as a situation, in which the signaler has more information available regarding an imminent decision compared to the receiver, hidden action is defined as the state where the signaler chooses an, for the receiver, unobservable level of effort regarding their agreement [31]. Vendors confirm that they acquire web assurance seals to Increase transparency in general. As web assurance seals expose information about various characteristics of the vendor, consumers might value such candor providing an advantage over other vendors. Also, vendors Use seals as a marketing tool through exploiting the seal's popularity. As one vendor stated: "The public image of a certified company is always better". Consumers confirm this intention, mentioning that web assurance seal Increase vendors' reputation because "web assurance seals serve as evidence that the certified online shop possesses some kind of incumbency". More specifically, participants acknowledged that seals function as proof for successful transaction history.

Within the area of hidden information, vendors aspire to Signal integrity as one vendor stated: "By using a seal, we want to be reputable towards our consumers". Consumers have a more nuanced view of how web assurance seals can render hidden information. Consumers perceive quality-related information such as Perceive vendor, website, and product quality. Vendor quality outlines an effect related to the vendor's external representation as well as internal processes. Regarding the vendor's external representation, a consumer stated that "web assurance seals signal the integrity of a 
vendor" (e.g., not being a malicious vendor) because vendors adhere to corresponding legislation or seal requirements, matching vendors' intentions. Concerning internal processes, consumers described that web assurance seals attest superior internal processes such as fast delivery processes or qualified personnel. The Perceive website quality effect is related to the superiority of the website or interface used to purchase goods online. For example, some consumers stated that seals indicate high ease of use of a website. Lastly, Perceive product quality is linked to the quality of the products offered in three dimensions: first, products are delivered as described, second, products exhibit certain idiosyncrasies such as fair trade, and third, products are not counterfeit.

Furthermore, we found the effects of web assurance seals on consumers that can be considered to constitute signals to overcome hidden actions from a signaling theory perspective. Consumers argue that web assurance seals ensure a low level of fraud potential, which lowers their risk perception (ex-ante), as well as that web assurance seals, represent measures that ensure recovery of consumers' conceded assets in case something unexpected will be happening (ex-post). Hence, Perceive risk minimization as an effect was framed. Similarly, we found Perceive Safety as an often conceived and overarching effect. As consumers stated, when noticing web assurance seals "online shopping feels safer". In general, certified websites communicate a safe and reliable way of doing online shopping, in which (potential) consumers do not have to conduct safety and security checks on their own (as far as possible). Given the e-commerce contexts, our study further unveiled intentions and effects related to consumers' perceived levels of IT-security, data protection as well as consumer protection. The effect Perceive IT-security is related to perceived technical security safeguards and measures applied by the online vendor and their respective information systems. A consumer stated that "seals confirm the prevention of information and data abuses". Vendors' intent to Signal data protection match with the effect Perceive data protection. Participants agreed that web assurance seals assure a confidential and safe usage of their data, which is becoming more and more important in modern electronic markets. Regarding vendors' intention to Signal consumer protection, we also identified the corresponding consumer effect Perceive consumer protection. Participants acknowledged that the effect captures consumers' protection in case of misbehavior originating from the vendor. That is, some seals testify a money-back guarantee when products do not exhibit the characteristics as expected or promised by the online vendor. Some participants stated that issuing seal authorities may serve as arbiters for consumers given a potential dispute settlement.

\subsection{Web assurance seals influence consumers' affect}

Signaling literature acknowledges that receivers, depending on their idiosyncrasies, interpret signals differently [99]. Receivers' interpretation is outlined as the process of translating signals into perceived meaning [11]. We found that web assurance seals as signals influence consumers' affect (i.e., beliefs, emotions, and attitudes) [64, 120] and hence, stimulate cognitive trust-building processes [49]. For instance, the effect Induce interest captures a rather positive belief or attitude [21]. 
One participant mentioned that web assurance seals increase her or his general interest in the seal itself and how it has been obtained (i.e., assessment process). In this regard, effect Induce interest can be considered a precursor of trust. Herein we adopt the definition of trusting belief [83] for the identified Induce Trust effect further taking into account trust, trustworthiness, as well as trust transference [73]. Participants stated that web assurance seals verify the trustworthiness of online shops due to the examination of an independent third-party. Participants also mentioned that "seals support my trust in an online shop because I trust the seal issuing instance", referring to trust transference. Increasing consumers' trust in the vendor is also one main intention of online vendors when acquiring web assurance seals. Contrary, Induce apathy emerged as an effect that captures consumers' emotions of apathy or indifference [78]. Some participants delineated that the simple presence of web assurance seals does not "arouse or influence me in any way". In contrast, to Induce apathy, in which web assurance seals "only" facilitate a state of indifference, the effect Induce skepticism - a disbelief [92]—has an opposing and dismissive impact. Participants stated that, when seeing web assurance seals, they are not acquainted with, they tend to question the seriousness and reliability of the respective vendor ("When seeing an unfamiliar seal I feel rather insecure than more secure").

\subsection{Web assurance seals influence stakeholders in the environment}

Signals are not only used to bridge information asymmetries between the signaler and an individual but also between the signaler and a collective whole - the signaling environment [11]. Therefore, the meaning assigned to a signal is not only a function of the receivers' interpretation (e.g., consumers, competitors, or suppliers) but also of a collective belief (e.g., the market in general) [59]. In line with this, we found that vendors acquire web assurance seals to "achieve competitive advantages over other vendors", framed as Achieve competitive advantages. In this regard, vendors also stated that web assurance seals Increase Comparison between competitors as "consumers evaluate seals and can compare an offer with other trustworthy offers". Some vendors intend to acquire web assurance seals because they feel Pressure from stakeholders (e.g., the public, consumers, competitors, suppliers, or governmental institutions). Vendors mentioned that they have to follow certain mandatory or voluntary requirements to be successful in their respective markets. In some cases, vendors even hope to ease their access to markets, framed as Gain market access because web assurance seals prove the compliance to minimum standards making the vendor eligible to enter a market.

\subsection{Web assurance seals lead to internal improvements of vendors}

The last category considers intentions of vendors to acquire web assurance seals that do not occur and act as signaling effects on the consumer side (at least not directly) but aim to improve vendors' internal conditions, thus representing the internal perspective (Table 1). When undergoing an attestation process, vendors value to Gain access to experts. Seal authorities' profound knowledge and experience in online 
vendors' businesses and technological and organizational safeguards can be regarded as complementary resources that can be leveraged to improve existing systems and processes. Through web assurance seals, a vendor's IT security standards can be assessed and improved (if necessary) as shown by the intention Increase IT security. As one vendor stated: "with seals, we also check our existing systems with regards to security aspects". Likewise, vendors aspire to Achieve legal conformity. The seal attestation process provides vendors support for improving the conformity regarding legal requirements of an online vendor's business, particularly by reviewing online vendors' general terms and conditions as well as related legal texts. In doing so, seal attestations can note weak points regarding legal compliance, which might have led to penalties from consumers in the future. Similarly, vendors mentioned that internal quality and productivity are improved through the assessment process. While achieving these internal improvements, vendors also intend to Increase consumer satisfaction: "It is part of our consumer service to provide [...] a degree of security for the consumer". Finally, vendors claim that acquiring seals help them to Achieve a better web search ranking: "appearance at the top of a Google search". Nevertheless, while the specific search algorithms are opaque and constantly evolving, the online community dealing with search engine optimization remains uncertain whether embedding independent reviews and seals impacts search results.

While these intentions to acquire web assurance seals cannot be considered to signal certain hidden information or actions of the vendor nor do they influence consumers' affect, they indirectly impact the signaling process because they positively influence the signaling fit. Signal fit is a characteristic of the signal and outlined as the correlation between the idiosyncrasies of a signal and the unobservable quality of the signaler [11]. Internal improvements positively affect signaler's quality resulting in an increased alignment between the signal and the true quality of the signaler, thus increasing signal fit.

\section{Comparing effect and intention weighting}

\subsection{Effect selections and rankings}

Following Schmidt et al. [109], we let the consumer and seal authority independently pare down and rank the lists of web assurance seal effects. After the selection phase, the participants from the consumer panel deemed 11 out of 15 effects important. With selection rates of $90 \%$, Perceive data protection and consumer protection were rated among the most important effects next to Induce trust and Perceive risk minimization. In contrast, only $14 \%$ marked Induce interest and $38 \%$ chose Induce apathy as important effects. Analog, we analyzed web assurance seal effects from the seal authority panel after the selection phase. All seal authority participants chose Perceive vendor quality, data protection, consumer protection, and Increase purchase intention as being relevant to them. Induce apathy (32\%) and Induce skepticism (74\%) are the least often chosen effects among seal authority experts, however, Induce skepticism was still considered for the ranking phase given a threshold of $45 \%$. 
To be able to compare the ranking results, we calculated the mean rank (=sum of means/number of data points of each effect). Overall (and after the secondranking phase), the top three effects that consumers named when seeing web assurance seals are Perceive consumer protection (mean rank $=3.52$ ), risk minimization (mean rank $=4.38$ ), and safety (mean rank=4.76). Contrary, seal authority experts' first three effects were Induce trust (mean rank=1.20), Perceive safety (mean rank $=2.20$ ), and risk minimization (mean rank=4.20). On the other end, consumers rated Perceive vendor quality (mean rank $=7.00$ ), website quality (mean rank $=8.38$ ), and product quality (mean rank $=9.44$ ) as least important, while web assurance seal experts ranked Increase vendors' reputation (mean rank $=7.40$ ), Perceive website quality (mean rank $=8.80$ ), and Induce skepticism (mean rank $=9.40$ ) as the three least important effects. The selection and ranking results of consumers' perceived web assurance seal effects are depicted in Table 5.

\subsection{Intention selections and rankings}

Our results show that nine intentions to acquire web assurance seals were deemed important by at least $45 \%$ of vendor experts. Signal integrity $(100 \%)$ was the most often selected intention. With selection rates of $93 \%$ Acquire consumers and Increase consumers' trust were the second most selected intentions, followed by Increase consumer satisfaction with a selection rate of $87 \%$. Yet, the least often selected intentions are Increase comparability with $20 \%$ and Gain market access $27 \%$ selection rates. Applying also a 45\%-threshold for seal authority panelists, experts selected eight intentions among which Achieve competitive advantages (84\%), Signal integrity (79\%), and data protection (68\%) were the most often chosen intentions to acquire web assurance seals in e-commerce. On the other end, only $5 \%$ chose Increase comparability, 21\% Achieve better web search ranking, and $26 \%$ Gain market access.

The top three intentions for vendors to acquire web assurance seals were Increase consumers' trust (mean rank=1.33), Signal integrity (mean rank=2.83), and Increase consumer satisfaction (mean rank $=3.33$ ). This was partially supported by the opinions of seal authority experts. They ranked Increase consumers' trust (mean rank =1.20), Acquire consumers (mean rank=2.60), and Signal integrity (mean rank $=3.00$ ) as most important. On the other hand, vendors ranked Use seals as a marketing tool (mean rank=6.67), Signal data protection (mean rank $=7.83$ ), and Increase IT security (mean rank $=8.67$ ) as the least three intentions to acquire web assurance seals for their online shops. Experts from the seal authority panel ranked, similarly to the vendor experts, Signal data protection (mean rank $=5.40$ ) among the last three intentions. The other two are Increase consumer satisfaction (mean rank $=6.00$ ) and Achieve competitive advantages (mean rank=7.00). The selection and ranking results of vendors' intentions to acquire web assurance seals are depicted in Table 6. 


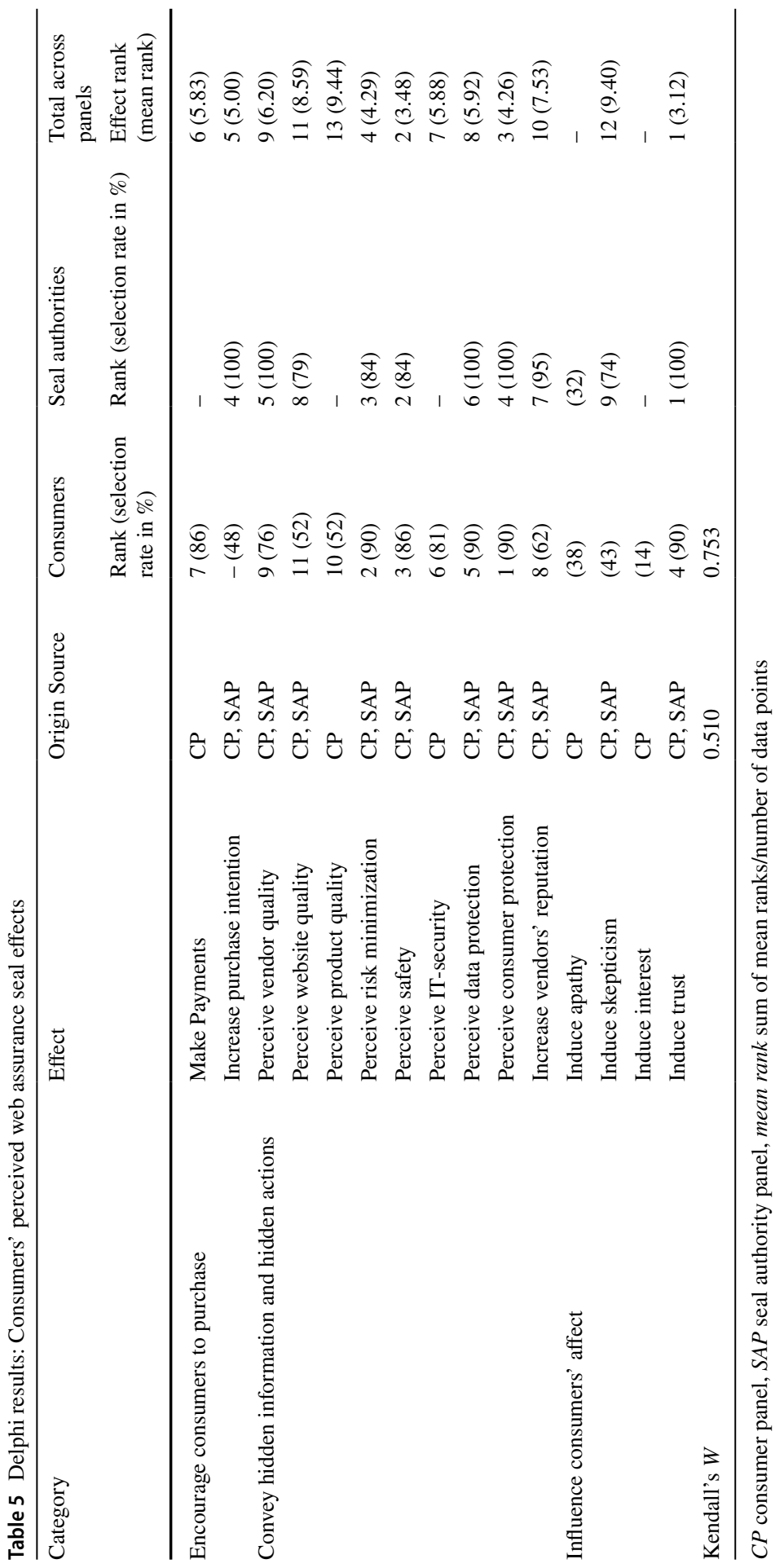




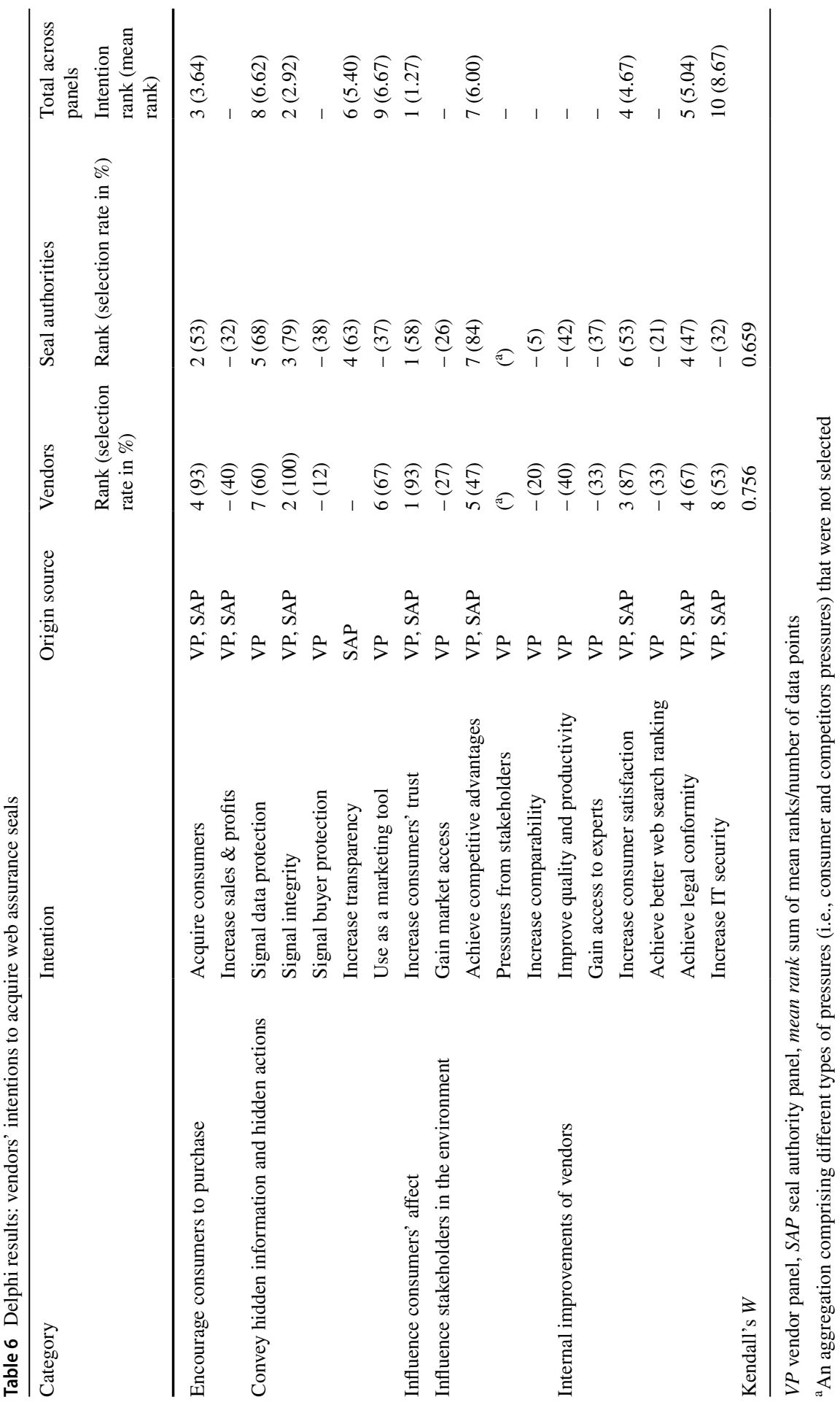




\section{Discussion}

This study aimed to provide a multi-perspective view on web assurance seals to extend our understanding of web assurance seal effectiveness. We started with identifying both, effects that occur when consumers perceive web assurance seals and intentions of vendors to acquire web assurance seals. We did so by applying a multiperspective Delphi study with three panels comprising consumers, vendors, and seal authority experts. Synthesizing the results from the respective panels not only constitutes a unique way to research web assurance seal effectiveness but enables to contrast consumer perceptions and vendor intentions to come up with novel insights that can provide a basis for research to move forward.

\subsection{Comparing vendors' intentions and consumer's perceptions}

When revisiting the previously presented results, it becomes evident that we uncovered a mismatch regarding vendors' intentions to acquire web assurance seals and consumers' perceptions of web assurance seals, which has several implications for web assurance seal research.

First, we show that the importance of effects and intentions identified in consumer and vendor panels differ. Based on the cumulated results from the consumer and the seal authority panel, Induce trust (mean rank $=3.12$ ), Perceive safety (mean rank $=3.48$ ), and Perceive consumer protection (mean rank $=4.26$ ) were the most important effects that consumers perceive when recognizing web assurance seals. Accumulating results from the vendor and seal authority panel, Increase consumers' trust (mean rank $=1.27$ ) is also the most important intention to acquire web assurance seals. Yet, the second and third most important intentions are Signal integrity (mean rank =2.92) and Acquire consumers (mean rank=3.64), therefore, indicating the first hint for a mismatch between consumers' perception of and vendors' intentions to acquire web assurance seals.

Second, we analyzed the identified effects and intentions within the respective theoretical categories. While consumers and vendors both agree that web assurance seals aim to encourage consumers to purchase, we identified several mismatches between the other theoretical categories. Starting with the category web assurance seals aim to convey hidden information and hidden actions, the study results show that vendors and consumers both value web assurance seals as signals to reduce prevalent information problems (e.g., hidden information or action). Yet, the type of information or action to be transferred in the respective signals such as seals and how they are perceived by stakeholders differs substantially (see Sect. 6.2 for a detailed discussion).

The third rationale that underlines a mismatch between intentions and actual effects of web assurance seals, is the fact that a signal is not necessarily a tailored measure to be received by only one type of receiver (e.g., consumers) but by various receivers (e.g., consumers, competitors or the market in general) at the same time. In particular, we identified intentions were no counter-part effect could be identified. For instance, vendors intend to use web assurance seals not to address their 
consumers but their environment, as embodied in the category web assurance seals influence stakeholders in the environment, or acquire web assurance seals to achieve internal improvements (see Sect. 6.3 for a detailed discussion).

Finally, inspecting the category web assurance seals influence consumers' affect, one can derive an additional mismatch between vendors' intentions and consumers' perceived effects. Whereas vendors aim to increase trustworthiness, consumers perceive a far more diverse and surprising set of effects (see Sect. 6.4 for a detailed discussion).

\subsection{Comparing study findings with prior literature on web assurance seals' effects on consumers}

Our study supports the refinement of our understanding regarding the three-in web assurance literature often researched effects-trust, perceived assurance, and purchase intention. We confirm that increasing consumers' trust is an important effect, given the high ranks in multiple panels (rank 1 seal authority and vendor panel, rank 4 consumer panel). More importantly, our results confirm that trust takes a dual form in the context of web assurance seals. First, consumers' trust in online vendors is increased because information asymmetries are reduced and web assurance seals confirm vendors' integrity, competence, and benevolence. Second, the mechanism of trust transfer takes place to increase consumers' trust as highlighted by diverse consumers in our panel: "Online shops that display seals are trustworthy because those institutions that issued the seal are trustworthy”. Assuming that a seal authority is trustworthy, a seal can establish a cognitive association between a certified vendor and a seal authority whereby a consumer's trust in a seal authority is transferred to a certified vendor [18]. Although prior studies on web assurance seal effectiveness acknowledge the potential occurrence of trust transference [41, 54], existing studies have neglected to test whether and how trust transference takes place in the context of web assurance seals. We thus recommend seal research to consider the duality of trust when analyzing seal effectiveness. Prior research has already shown that consumers' perceived credibility of the seal authority plays an important role in achieving seals' intended effects [127]. A fine-grained analysis of trust mechanisms may help to understand boundary conditions of seal effectiveness, for example, in contexts where seal authorities are not perceived as trustworthy, and thus trust transference is disturbed. Hence, online vendors should be cautious when selecting seal authorities because consumers' perceived credibility and trustworthiness of these authorities might have an impact on acquired seal effectiveness.

This research also provides a more nuanced view on increasing consumers' perceived assurance. Prior research has mostly operationalized perceived assurance regarding reducing security and privacy concerns of consumers $[51,54,73]$. While our study findings confirm that vendors acquire seals to convey secure, reliable, and confidential handling of consumers' data (i.e., intention Signal data protection), consumers report that they also Perceive vendor, website, or product quality when seeing web assurance seals. In addition, we not only found evidence for context-specific effects on consumers depending on the objectives and content of the seal but also for 
the fact that consumers derive effects from seals independent of their actual specification and that misconceptions may arise about seals' true meaning. For instance, Perceive safety was referred to as: "I feel saver when recognizing seals" by one consumer, while another stated: "The online shop displaying seals seems to be safer than non-certified shops". The concept of safety, typically defined as the absence of risk, is very broad and it remains vague what consumers are actually expecting from the seal. Similarly, the effect Perceive risk minimization reflects a broader perception of seals. On the other hand, Perceive consumer protection captures the very specific idea of a shop that has to provide a money-back guarantee in case of unsatisfying delivery, which is not part of every seal [41, 61]. As one consumer stated: "I see seals as a guarantee of low fraud potential and that I will receive my money back, in case, I do not want the product anymore". Thus, our findings highlight that some consumers may form a general assurance perception of seals (e.g., feeling safe and expecting fewer risks), while others may have specific expectations regarding the assurances a seal provides (e.g., providing money-back guarantees). Early research findings on seals might provide reasoning because it was shown that an expectation gap might exist between the intended assurances and perceived qualities of web seals - even when the seal in question has been widely adopted [39, 58, 93]. Such an expectation gap may result because consumers often do not understand what seals are, what they stand for, and how to interpret and classify the information they intend to convey $[55,85,86]$. We, therefore, recommend research on web assurance seal effectiveness to take a look at the content of the seal under examination (e.g., security vs. quality seal) and prevalent information asymmetries (e.g., hidden information concerning product qualities). Then, researchers should identify (context-specific) effects on consumers to better operationalize the effect perceived assurance. In addition, research may control for whether consumers understand the assurances the seal under examination provides to ensure that indented effects are perceived, or whether a limited understanding leads to confounding effects, such as only increasing consumers' general perception (e.g., Perceive safety and risk minimization). Online vendors should also carefully elaborate on the content of seals to ensure that they are signaling their unobservable qualities to consumers [61].

Regarding increasing consumers' purchase intention, our study shows mixed and surprising findings. Whereas each seal authority expert selected the effect Increase purchase intention, only $47.62 \%$ of the consumers selected this effect. Instead, consumers perceive seals as guarantees for secure payments: "I believe that payment transactions with certified online shops, in general, are more secure than with shops that do not own a certificate."-leading to the assumption that seals indirectly impact their purchasing behavior. In line with this, we recommend seal research to consider identifying potential mediators impacting the influence of seals on consumers' purchase intentions. Trust and perceived assurance, for example, have been regarded as antecedents for consumers' behavioral intentions [54, 73, 84], and thus seals might have an indirect effect on purchase intention via increasing consumers' trust and perceived assurance [70]. We thus propose that researchers should not only analyze the direct effect of seals on purchase intention but also examine the role of potential mediators for consumers' purchase intention to control for indirect effects of seals. Our recommendation is consistent with recent calls for contextualized 
theory (i.e., considering context-specific mediation and moderation effects) in the broader IS discipline [38, 94].

\subsection{Comparing study findings with prior literature on vendors' intentions to acquire seals}

We identified the diverse intentions of online vendors to acquire web assurance seals. Some of these intentions are consistent with prior literature, such as Increase sales and profit [12, 16, 29, 44], Improve quality and productivity [35, 79, 89], and Achieve competitive advantages $[28,35,118]$. Our results thus provide a first indication that there is a set of factors impacting organizations' intentions when deciding to acquire a web assurance seal that is independent of the actual contexts, such as electronic markets or environmental certification. Contrary, we found intentions that were not present in prior literature and are specific to electronic markets, including Signal data protection, and Achieve legal conformity. These differences mainly relate to the actual content of the seal (i.e., what is certified), such as security and privacy requirements for online platforms. Consequently, our findings also support our assumption that intentions in electronic markets differ from motives in related disciplines.

Moreover, our results demonstrate that web assurance seals do not only serve as signals to bridge information asymmetries between consumers and vendors but also to address other stakeholders in the signaling environment. In line with signaling theory, the interpretation of a signal is not only a function of a single receiver but can also inform collective beliefs [59]. Therefore, it can be argued that a certain signal can be received and evaluated by various receivers. Nevertheless, our results confirm that the intended signal objective might diverge, such as to comply with pressures from external stakeholders or to achieve advantages over competitors, requiring a multi-receiver perspective to study signal effectiveness. This situation can further be impaired by environmental noise that originates from the signaling environment, other signalers with similar aims or external referents [11]. Consequently, when planning to acquire web assurance seals, vendors should critically evaluate who may be receiving the signal and then acquire a web assurance seal that best fits the information problem to be overcome.

Finally, our results show that vendors acquire seals to achieve internal improvements (e.g., Increase IT security or Gain access to experts). Nevertheless, our brainstorming phases reveals that 12 out of 18 intentions are related to external intentions, which were also more often selected and higher ranked than internal intentions. Revisiting our initial question, whether online vendors are more driven by external than internal intentions (see Sect. 2.2.1), we can conclude that our results give an initial indication that external intentions are more important in electronic markets. In addition, taking a signaling theory perspective, we propose that internal intentions to acquire web assurance seals also improve signaling fit as described above and, therefore, improving signal effectiveness indirectly. Consequently, when analyzing web assurance seals effectiveness, researchers should evaluate the indirect or 
long-term effects of web assurance seals too, to better understand and predict web assurance seals' true effectiveness.

\subsection{Unintended effects of web assurance seals}

Although we found that trust, as a belief, is the most important effect when recognizing web assurance seals as well as intention to acquire web assurance seals, our findings, surprisingly, also revealed unintended effects of seals on consumers, such as Induce apathy and Induce skepticism. We assert that due to variances in signal interpretation among receivers $[11,61]$ unintended side effects can arise. Our results show that consumers felt emotionally apathetic when recognizing web assurance seals: "web assurance seal do not arouse me in any way". Signaling theory provides rationales as apathy might be a result of weak signaling strength, for example, because of a low signaling fit [8]. Moreover, consumers even mentioned opposing or dismissing beliefs when seeing web assurance seals such as Skepticism. One consumer stated: "When seeing unfamiliar web assurance seals, I question the seriousness of the online shop". As such, the signal failed to achieve its intended effect, which further emphasizes a mismatch between vendors' intentions and consumers' perception of web assurance seals. More importantly, this is a surprising finding because previous studies have only explicitly identified trust as a positive effect of web assurance seals. With this study, we show that extremely opposing effects (i.e., skepticism) may be induced for consumers. Both, from theoretical as well as practical perspectives, this finding is of highest relevance because it provides deeper insights about the volatility of consumer perceptions in digital contexts. Thus, signal effectiveness may be balanced on a razor edge.

According to the rationales of signaling theory, an explanation for the emergence of skepticism might be a lacking signaler's honesty. Signaler's honesty defines the degree to which the signaler is capable of meeting the characteristics as promised by the signal [19]. Such low signaler's honesty was also reported in negative media news about seals throughout the last years. Media frequently warns consumers that online vendors may embed fake seals on their websites. Similarly, blog entries [36] and consumer reports [76] instigate consumers to be skeptical about issued web seals. Consumers' skepticism toward seals may also be strengthened due to famous incidents that became public, as in the case of TRUSTe [106]. TRUSTe provides web seals assuring consumers that businesses' privacy practices comply with specific privacy standards. TRUSTe, however, has been given a $\$ 200,000$ fine by the US Federal Trade Commission after consumers were deceived into thinking that TRUSTe was doing proper auditing of those organizations displaying its web seal [22]. In fact, TRUSTe allowed commercial websites and mobile apps to display their web seal but did not verify whether these websites and apps were indeed meeting privacy standards [72].

While negatively connoted, affective influences have not been part of prior investigations on seal effectiveness, we recommend seal research to control for potential unintended effects, such as consumer skepticism. Likewise, research might add moderators on the relationship between the presence of seals and their intended 
effects, for example, consumers' willingness to depend on the seals or general attitude toward the seals to control whether consumers value the seal in general. Including these variables in theory building, especially potential effect moderators, may help to get a more comprehensive picture of seal effects and define potential boundary conditions helping to uncover origins of the seal effectiveness variation. A deeper understanding will also help vendors and seal authorities to prevent such unintended effects.

\section{Conclusion}

Previous web assurance seal literature has been impeded by the fact that research findings were based on a unilateral view on web assurance seals. That is, web assurance seals have been researched either form the vendor or the consumer perspective. However, the nature of web assurance seals, as shown in this study, contradicts this approach. Hence, the paper at hand has examined web assurance seals in a novel way, that is, by using a multi-perspective approach that advances our understanding of the phenomenon under investigation. In doing so, we reveal a mismatch between perceived and intended effects of web assurance seals.

\subsection{Theoretical implications}

Our study has several implications for research (Table 7). Although embodying valuable contributions, previous research has applied a lopsided (and hence limited) view on web assurance seals. That is the analysis of web assurance seals from either a consumer (perceptions) [54, 83, 96], or vendor (intentions) perspective [29, 34, 103] only. To the best of our knowledge, this is the first study to utilize a multiperspective investigation on web assurance seals in e-commerce. Using signaling theory as our theoretical lens, we derive five aggregated categories of intentions and effects that enable better comparison and theoretical grounding. For each category, we show an incongruence between what web assurance seals as signals are intended by vendors to transfer versus what is truly perceived by consumers. We not only reveal that the importance of effects and intentions identified in consumer and vendor panels differ but also revealed intentions were no counter-part effects could be matched and vice versa. For example, whereas vendors aim to increase trustworthiness, consumers perceive a far more diverse set of effects. These advancements expand our knowledge to allow for a more differentiated and nuanced analysis of web assurance seal effectiveness.

Second, while extant research analyzes organizations' motivations to adopt certifications that are based on ISO standards [34, 77], it remains unclear whether motives are applicable and relevant in electronic markets, which is an essential context in everyday life. By conducting a Delphi study with stakeholders from electronic markets and identifying 18 intentions to acquire a web seal, we were able to confirm that certain intentions of related streams are applicable in electronic markets, proving that that certain intentions are context-independent. Additionally, 


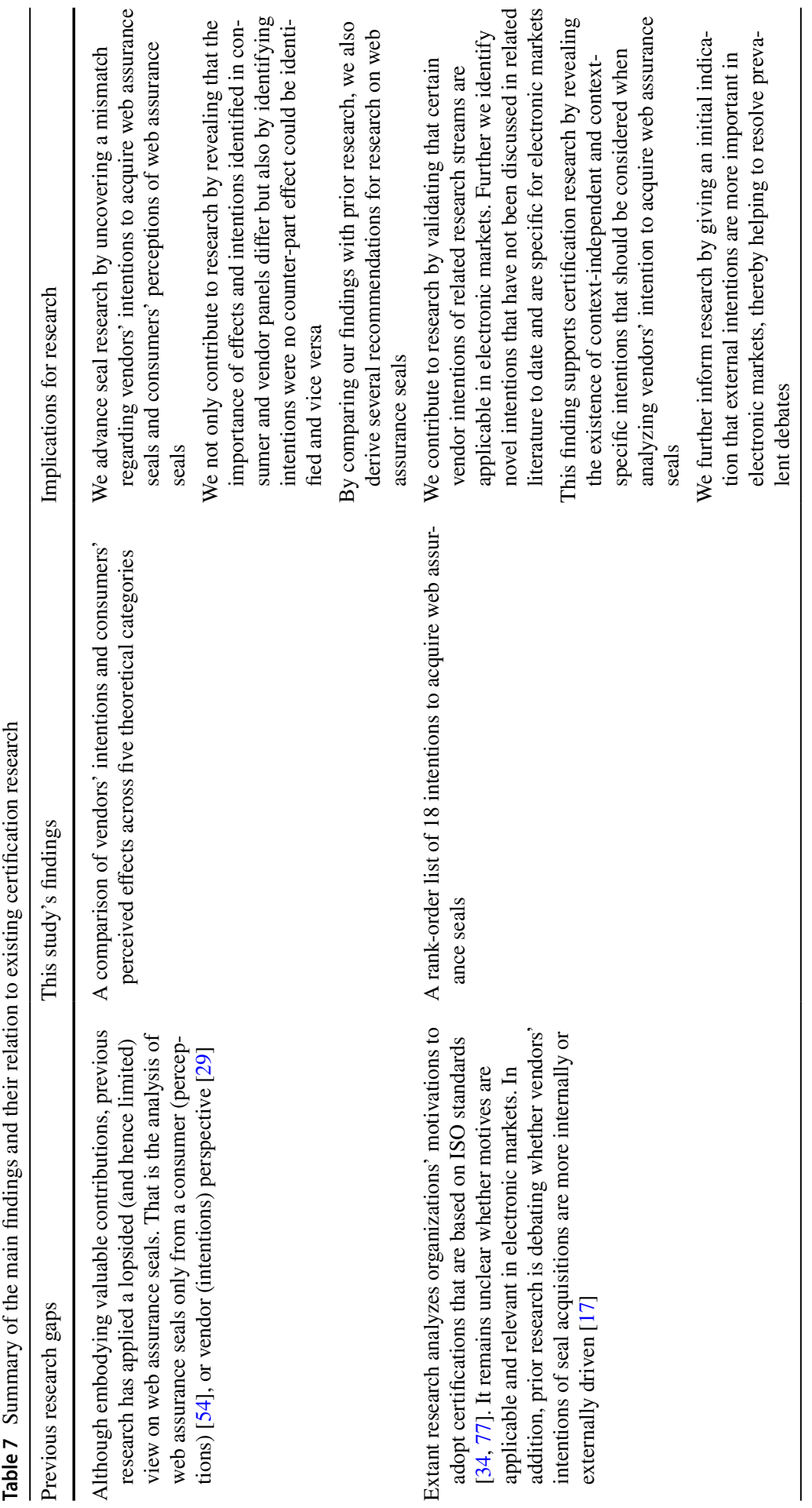




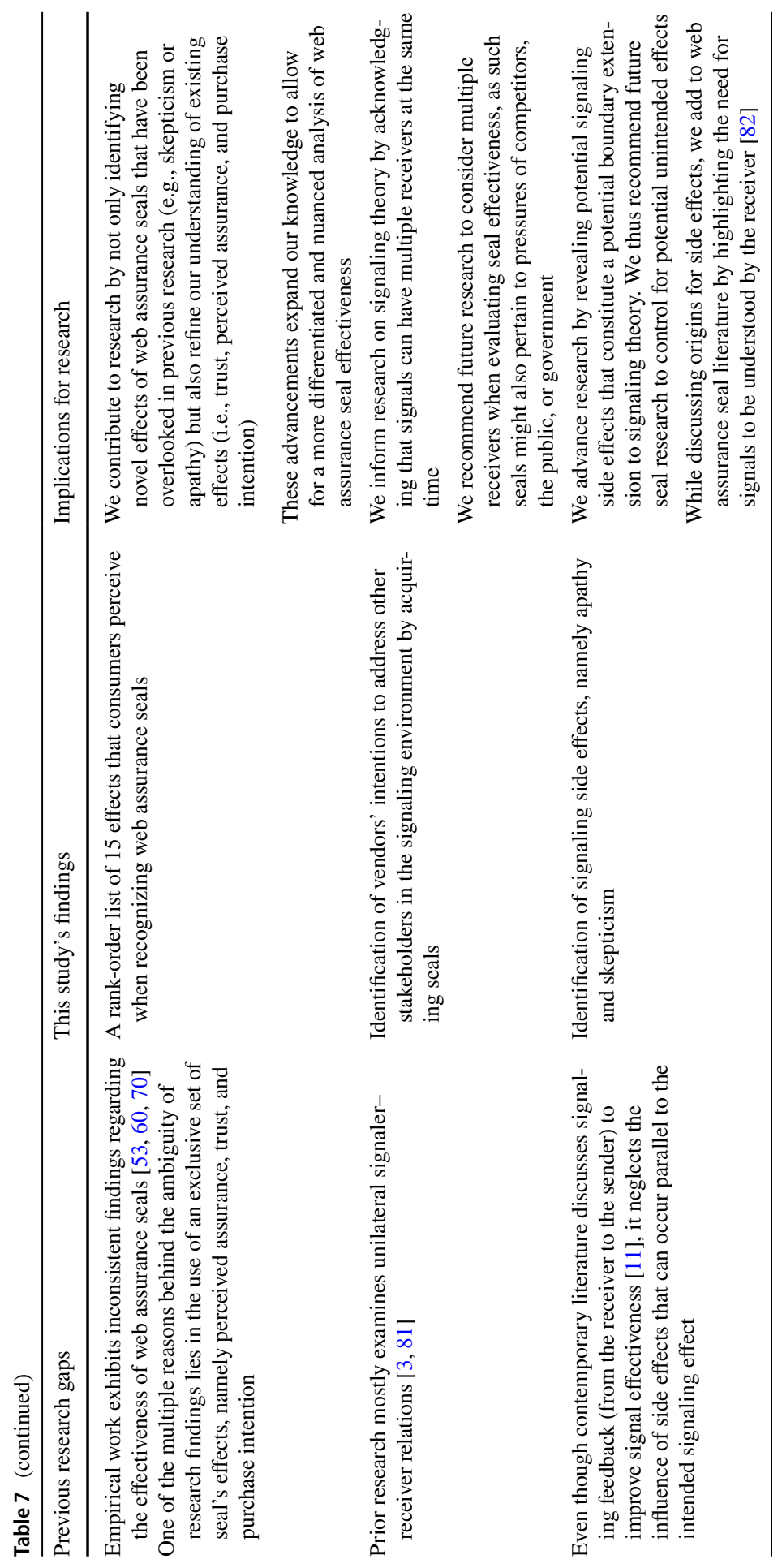


our Delphi study leads to the identification of novel motives that have not been discussed in related literature to date and are specific for electronic markets, such as Signal data protection and Achieve legal conformity. We further inform research by giving an initial indication that external intentions are more important in electronic markets, thereby helping to resolve prevalent debates about whether vendors' intentions of seal acquisitions are more internally or externally driven [17].

Third, we provide a more nuanced analysis of the effects of web assurance seals, discussing 15 effects compared to prior research that mostly uses an exclusive set of three effects, namely perceived assurance, trust, and purchase intention. We not only refine our understanding of these effects but also identify effects of web assurance seals that have been overlooked in previous research (e.g., skepticism or apathy). By relating our findings to prior research, we derived several recommendations for research on web assurance seals (see Table 8 in Sect. 7.3). These advancements

Table 8 Summary of recommendations for future research on web assurance effectiveness

\begin{tabular}{ll}
\hline Related variables & Recommendations \\
\hline Trust & We propose that research should consider the duality of trust \\
& when analyzing seal effectiveness. First, consumer's trust in \\
& online vendors is increased because information asymmetries \\
& are reduced and seals confirm vendor's integrity, competence, \\
& and benevolence. Second, trust transfer takes place if consum- \\
& ers perceive that a seal authority is trustworthy, a seal than can \\
& establish a cognitive association between a certified vendor \\
& and a seal authority whereby a consumer's trust in a seal \\
& authority is transferred to a certified vendor
\end{tabular}

Perceived assurance

Purchase intention

Consumers' understanding of seals

Receiver of seals

Skepticism and Apathy

Consumers' general perception of seal
We propose that research should take a look at the content of the seal under examination (i.e., security vs. quality seal) and prevalent information asymmetries (i.e., hidden information concerning product qualities), and identify (context-specific) effects on consumers to better operationalize the construct perceived assurance

We propose that research should not only analyze the direct effect of seals on purchase intention but also examine the role of potential mediators (i.e., trust, perceived assurance) for consumers' purchase intention to control for indirect effects of seals

We propose that research should control whether consumers understand the assurances a seal provides to ensure that indented effects are perceived

We argue that research should consider multiple receivers when evaluating seal effectiveness, as such seals might also pertain to pressures of competitors, the public, or government

We recommend research to control for potential negative effects of seals, such as consumer skepticism

We recommend research to add moderators on the relationship between the presence of seals and their intended effects, for example, consumers' willingness to depend on the seal or general attitude towards the seal to control whether consumers value the seal in general 
expand our knowledge to allow for a more nuanced analysis of web assurance seals' effects on consumers.

Fourth, our findings contribute to the signaling theory knowledge base by demonstrating that scholars should consider a shift from researching unilateral signaler-receiver relations to more complex signaler-multi-receiver relations (e.g., consumers and competitors), considering multiple actors in the signaling ecosystem [71]. Whereas prior web assurance seal research was mainly on the isolated influence of one or more signals on a single target group (e.g., consumers) [3, 81], with this study we provide deeper insights about why vendors acquire seals to influence their signaling environment.

Finally, with this study, we also contribute to signaling theory literature, as we uncover an additional concept worth spending consideration: signaling side effects. Signaling side effects constitute a potential boundary extension to signaling theory. Even though contemporary literature discusses signaling feedback (from the receiver to the sender) to improve signal effectiveness, and the influence of the signal environment being a source of signal distortion [11], it neglects the influence of side effects that can occur in parallel to the intended signaling effect. In this way, the identified signaling side effects apathy and skepticism may play an important role concerning the complexity of evaluating signal effectiveness. While discussing origins for side effects, we also add to web assurance seal literature by highlighting the need for signals to be understood by the receiver [82]. Otherwise, web assurance seals might not only be ignored but also induce negative and counteracting side effects.

\subsection{Practical implications}

Besides theoretical implications, this work also has implications for practice. First, caused by the mismatch of web assurance seals perceptions and intentions, vendors should crucially evaluate web assurance seals content with, first, their aims regarding the type of information problem to overcome (e.g., unobservable vendor characteristics to signal) and second, evaluate (e.g., utilizing web tracking mechanisms) what their respective consumers perceive or value when recognizing web assurance seals. Second, for seal authorities, we provide the groundwork to improve the seal design to suppress undesirable side effects that weaken the quality and strength of web seals as signals. Third, based on our finding that web assurance seals may not only be received by consumers but also by competitors, legal authorities or the market in general (i.e., collective belief), seal authorities should tailor or multipurpose their web assurance seals as to better target the individual audience or various audiences, respectively.

\subsection{Limitations and future research}

This study is subject to limitations. First, our results are based on the responses from initially 60 participants of which 25 (14 consumers, six vendors, and five seal 
authority experts) participated in all four rounds, leaving concerns regarding a sufficient sample size open. However, contemporary Delphi studies within the IS area exhibit even smaller sample sizes [48, 100], and, following Okoli and Pawloski [95], samples are not required to be statistically representative. However, we believe that we have produced results that exhibit above-average reliability, due to the combination of three separate, yet mutually supporting panels with the same goal. Second, as with every Delphi study, responses given by the participants are rather subjective. This also becomes evident when looking at the consensus calculated between participants (cf. Tables 5, 6). Besides, responses from seal authorities and vendors might be biased because experts wanted to emphasize the positive aspects of web assurance seals to ensure their effectiveness. Nevertheless, compared to other recent method-related studies, the consensus among participants was moderate to high, which we acknowledge as acceptable [100].

In general, Delphi studies are often treated as explorative starting points for further empirical investigations. We, therefore, first and foremost, call upon future research to investigate and validate the identified web assurance seal effects of consumers as well as intentions to acquire web assurance seals for vendors. By comparing our results with prior research, we were able to derive particular recommendations for future research on web assurance effectiveness, summarized in Table 8. Especially, we encourage scholars to examine the most important effects revealed herein as well as controversial effects such as Apathy and Skepticism. In particular, and referring back to the two latter mentioned effects, the influence of consumers' personality traits on web seal effectiveness may be of prime interest for future research.

Acknowledgements Open Access funding provided by Projekt DEAL. Financial support for this work by the German Research Foundation (DFG) through the granted research project "A Decompositional Analysis of IT Certifications in Electronic Markets and their Effect on Platform Customer and Provider Perceptions" (BE 4308/4-1 and SU-717/10-1) is gratefully acknowledged.

Open Access This article is licensed under a Creative Commons Attribution 4.0 International License, which permits use, sharing, adaptation, distribution and reproduction in any medium or format, as long as you give appropriate credit to the original author(s) and the source, provide a link to the Creative Commons licence, and indicate if changes were made. The images or other third party material in this article are included in the article's Creative Commons licence, unless indicated otherwise in a credit line to the material. If material is not included in the article's Creative Commons licence and your intended use is not permitted by statutory regulation or exceeds the permitted use, you will need to obtain permission directly from the copyright holder. To view a copy of this licence, visit http://creativecommons.org/licen ses/by/4.0/.

\section{Appendix}

In the following, we summarize the exact wording of all questions asked during the brainstorming survey. We decided to include two questions in the consumer panel because verbalizing potential effects of web assurance seals is challenging for consumers compared to seal authority experts whose daily business is about web assurance seals. Yet, both questions aimed to derive potential web assurance seal effects. 
We considered potential differences in consumer responses across both questions during our data analysis.

\section{Consumers:}

(1) How does a web assurance seal help you shopping online?

(2) What properties do you associate with a web assurance seal?

Vendors:

(1) Which reasons motivated your company to have your online shop certified?

(2) Which reasons discouraged your company to have your online shop certified?

Seal authorities:

(1) What reasons motivate companies to have their online shops certified?

(2) What reasons prevent companies from having their online platforms certified?

\section{References}

1. Abraham, C., Boudreau, M.-C., Junglas, I., \& Watson, R. (2013). Enriching our theoretical repertoire: The role of evolutionary psychology in technology acceptance. European Journal of Information Systems, 22(1), 56-75. https://doi.org/10.1057/ejis.2011.25.

2. Adam, M., Niehage, L., Lins, S., Benlian, A., \& Sunyaev, A. Stumbling over the Trust Tipping Point: The effectiveness of web seals at different levels of website trustworthiness. In Proceedings of the 28th European conference on information systems (ECIS 2020), Marrakesh, Morocco (pp. 1-15).

3. Aiken, K. D., Shin, S., \& Pascal, V. (2014). An international investigation of source influence effects of Internet trustmarks. Journal of Internet Commerce, 13(2), 89-115. https://doi. org/10.1080/15332861.2014.934646.

4. Akins, R. B., Tolson, H., \& Cole, B. R. (2005). Stability of response characteristics of a Delphi panel: Application of bootstrap data expansion. BMC Medical Research Methodology, 5, 37.

5. Backhouse, J., Hsu, C. W., \& Silva, L. (2006). Circuits of power in creating de jure standards: Shaping an international information systems security standard. MIS Quarterly, 30, 413. https:// doi.org/10.2307/25148767.

6. Beck, N., \& Walgenbach, P. (2005). Technical efficiency or adaptation to institutionalized expectations? Organization Studies, 26(6), 841-866. https://doi.org/10.1177/0170840605054599.

7. Bergh, D. D., Connelly, B. L., Ketchen, D. J., \& Shannon, L. M. (2014). Signaling theory and equilibrium in strategic management research: An assessment and a research agenda. Journal of Management Studies, 51(8), 1334-1360. https://doi.org/10.1111/joms.12097.

8. Busenitz, L. W., Fiet, J. O., \& Moesel, D. D. (2005). Signaling in Venture Capitalist-New Venture Team Funding Decisions: Does It Indicate Long-Term Venture Outcomes? Entrepreneurship Theory and Practice, 29(1), 1-12. https://doi.org/10.1111/j.1540-6520.2005.00066.x.

9. Chang, M. K., Cheung, W., \& Tang, M. (2013). Building trust online: Interactions among trust building mechanisms. Information and Management, 50(7), 439-445. https://doi.org/10.1016/j. im.2013.06.003.

10. Clemons, E. K., Wilson, J., Matt, C., Hess, T., Ren, F., Jin, F., et al. (2016). Global differences in online shopping behavior: Understanding factors leading to trust. Journal of Management Information Systems, 33(4), 1117-1148. https://doi.org/10.1080/07421222.2016.1267531. 
11. Connelly, B. L., Certo, S. T., Ireland, R. D., \& Reutzel, C. R. (2010). Signaling theory: A review and Assessment. Journal of Management, 37(1), 39-67. https://doi.org/10.1177/014920631038841 9.

12. Corbett, C. J., Montes-Sancho, M. J., \& Kirsch, D. A. (2005). The financial impact of ISO 9000 certification in the United States: An empirical analysis. Management Science, 51(7), 1046-1059. https://doi.org/10.1287/mnsc.1040.0358.

13. Corbin, J. M., \& Strauss, A. L. (2015). Basics of qualitative research: Techniques and procedures for developing grounded theory. Los Angeles: Sage.

14. Di Gangi, P. M., Johnston, A. C., Worrell, J. L., \& Thompson, S. C. (2018). What could possibly go wrong? A multi-panel Delphi study of organizational social media risk. Information Systems Frontiers, 20(5), 1097-1116. https://doi.org/10.1007/s10796-016-9714-2.

15. DiMaggio, P. J., \& Powell, W. W. (1983). The iron cage revisited. American Sociological Review, 48(2), 147-160. https://doi.org/10.2307/2095101.

16. Disterer, G. (2012). Why firms seek ISO 20000 certification-A study of ISO 20000 Adoption. In Proceedings of the 20th European conference on information systems (ECIS 2012), Barcelona, Spain, 10-13 June (pp. 1-12).

17. Djofack, S., \& Camacho, M. A. R. (2017). Implementation of ISO 9001 in the Spanish tourism industry. International Journal of Quality \& Reliability Management, 34(1), 18-37. https://doi. org/10.1108/IJQRM-10-2014-0151.

18. Doney, P. M., Cannon, J. P., \& Mullen, M. R. (1998). Understanding the influence of National Culture on the development of trust. Academy of Management Review, 23(3), 601-620. https://doi. org/10.5465/AMR.1998.926629.

19. Durcikova, A., \& Gray, P. (2009). How knowledge validation processes affect knowledge contribution. Journal of Management Information Systems, 25(4), 81-108. https://doi.org/10.2753/MIS07 42-1222250403.

20. eMarketer. (2018). E-commerce share of total global retail sales from 2015 to 2021. New York: eMarketer. https://www.statista.com/statistics/534123/e-commerce-share-of-retail-sales-world wide/. Accessed 8 May 2020.

21. Evans, K. M. (1971). Attitudes and interests in education (2nd ed.). London: Routledge \& Kegan.

22. Federal Trade Commission. (2014). TRUSTe settles FTC charges it deceived consumers through its privacy seal program. Washington, DC: Federal Trade Commission. https:/www.ftc.gov/ news-events/press-releases/2014/11/truste-settles-ftc-charges-it-deceived-consumers-through-its. Accessed 8 May 2020.

23. Fisher, R., \& Chu, S. Z. (2009). Initial online trust formation: The role of company location and web assurance. Managerial Auditing Journal, 24(6), 542-563. https://doi.org/10.1108/0268690091 0966521.

24. Flynn, L. R., \& Goldsmith, R. E. (1999). A short, reliable measure of subjective knowledge. Journal of Business Research, 46(1), 57-66. https://doi.org/10.1016/S0148-2963(98)00057-5.

25. Friedman, M. (1937). The use of ranks to avoid the assumption of normality implicit in the analysis of variance. Journal of the American Statistical Association, 32(200), 675-701. https://doi. org/10.1080/01621459.1937.10503522.

26. Gao, L., \& Waechter, K. A. (2017). Examining the role of initial trust in user adoption of mobile payment services: an empirical investigation. Information Systems Frontiers, 19(3), 525-548. https ://doi.org/10.1007/s10796-015-9611-0.

27. Gefen, D., Karahanna, E., \& Straub, D. W. (2003). Trust and TAM in online shopping: An integrated model. MIS Quarterly, 27(1), 51-90. https://doi.org/10.2307/30036519.

28. González-Benito, J., \& González-Benito, O. (2005). An analysis of the relationship between environmental motivations and ISO14001 certification. British Journal of Management, 16(2), 133-148.

29. Gopal, A., \& Gao, G. (2009). Certification in the Indian offshore IT services industry. Manufacturing \& Service Operations Management, 11(3), 471-492. https://doi.org/10.1287/msom.1080.0234.

30. Gregg, D. G., \& Walczak, S. (2010). The relationship between website quality, trust and price premiums at online auctions. Electronic Commerce Research, 10(1), 1-25. https://doi.org/10.1007/ s10660-010-9044-2.

31. Hart, O., \& Holmström, B. (1987). The theory of contracts. In T. F. Bewley (Ed.), Advances in economic theory (pp. 71-156). Cambridge: Cambridge University Press. 
32. Hayes, A. F., \& Krippendorff, K. (2007). Answering the call for a standard reliability measure for coding data. Communication Methods and Measures, 1(1), 77-89. https://doi.org/10.1080/19312 450709336664.

33. Head, M., \& Hassanein, K. (2002). Trust in e-commerce: Evaluating the impact of third-party seals. Quarterly Journal of Electronic Commerce, 3(3), 307-325.

34. Heras-Saizarbitoria, I., \& Boiral, O. (2013). ISO 9001 and ISO 14001: Towards a Research Agenda on Management System Standards. International Journal of Management Reviews, 15(1), 47-65. https://doi.org/10.1111/j.1468-2370.2012.00334.x.

35. Heras-Saizarbitoria, I., Landín, G. A., \& Molina-Azorín, J. F. (2011). Do drivers matter for the benefits of ISO 14001? International Journal of Operations \& Production Management, 31(2), 192-216. https://doi.org/10.1108/01443571111104764.

36. Hoffman, C. (2014). All those "seals of approval" on websites don't really mean anything. https ://www.howtogeek.com/199240/all-those-seals-of-approval-on-websites-dont-really-mean-anyth ing/. Accessed 8 May 2020.

37. Hoffmann, C. P., Lutz, C., \& Meckel, M. (2014). Digital natives or digital immigrants? The impact of user characteristics on online trust. Journal of Management Information Systems, 31(3), 138171. https://doi.org/10.1080/07421222.2014.995538.

38. Hong, W., Chan, F. K. Y., Thong, J. Y. L., Chasalow, L. C., \& Dhillon, G. (2014). A framework and guidelines for context-specific theorizing in information systems research. Information Systems Research, 25(1), 111-136. https://doi.org/10.1287/isre.2013.0501.

39. Houston, R. W., \& Taylor, G. K. (1999). Consumer perceptions of CPA WebTrustSM assurances: Evidence of an expectation Gap. International Journal of Auditing, 3(2), 89-105. https://doi. org/10.1111/1099-1123.00051.

40. Hu, X., Lin, Z., \& Zhang, H. (2002). Trust promoting seals in electronic markets: An exploratory study of their effectiveness for online sales promotion. Journal of Promotion Management, 9(1-2), 163-180. https://doi.org/10.1300/J057v09n01_13.

41. Hu, X., Wu, G., Wu, Y., \& Zhang, H. (2010). The effects of web assurance seals on consumers' initial trust in online vendors: A functional perspective. Decision Support Systems, 48(2), 407-418. https://doi.org/10.1016/j.dss.2009.10.004.

42. Hui, K.-L., Teo, H. H., \& Lee, S.-Y. T. (2007). The value of privacy assurance: An exploratory field experiment. MIS Quarterly: Management Information Systems, 31(1), 19-33. https://doi. org/10.2307/25148779.

43. ISO. (2018). The ISO Survey. Geneva: International Organization of Standardization.

44. Kammoun, R., \& Aouni, B. (2012). ISO 9000 adoption in Tunisia: Experiences of certified companies. Total Quality Management \& Business Excellence, 24(3-4), 1-16.

45. Kaplan, S. E., \& Nieschwietz, R. J. (2003). A web assurance services model of trust for B2C e-commerce. International Journal of Accounting Information Systems, 4(2), 95-114. https://doi. org/10.1016/S1467-0895(03)00005-8.

46. Kasi, V., Keil, M., Mathiassen, L., \& Pedersen, K. (2008). The post mortem paradox: A Delphi study of IT specialist perceptions. European Journal of Information Systems, 17(1), 62-78. https:// doi.org/10.1057/palgrave.ejis.3000727.

47. Keeney, S., McKenna, H., \& Hasson, F. (2010). The Delphi technique in nursing and health research (1st ed.). Oxford: Wiley.

48. Keil, M., Tiwana, A., \& Bush, A. (2002). Reconciling user and project manager perceptions of IT project risk: A Delphi study. Information Systems Journal, 12(2), 103-119. https://doi.org/10.104 6/j.1365-2575.2002.00121.x.

49. Kim, D., \& Benbasat, I. (2006). The effects of trust-assuring arguments on consumer trust in Internet stores: Application of Toulmin's model of argumentation. Information Systems Research, 17(3), 286-300. https://doi.org/10.1287/isre.1060.0093.

50. Kim, D. J. (2008). Self-perception-based versus transference-based trust determinants in computermediated transactions: A cross-cultural comparison Study. Journal of Management Information Systems, 24(4), 13-45. https://doi.org/10.2753/MIS0742-1222240401.

51. Kim, D. J., Ferrin, D. L., \& Rao, H. R. (2008). A trust-based consumer decision-making model in electronic commerce: The role of trust, perceived risk, and their antecedents. Decision Support Systems, 44(2), 544-564. https://doi.org/10.1016/j.dss.2007.07.001.

52. Kim, D. J., Steinfield, C., \& Lai, Y.-J. (2008). Revisiting the role of web assurance seals in business-to-consumer electronic commerce. Decision Support Systems, 44(4), 1000-1015. https://doi. org/10.1016/j.dss.2007.11.007. 
53. Kim, D. J., Yim, M.-S., Sugumaran, V., \& Rao, H. R. (2016). Web assurance seal services, trust and consumers' concerns: An investigation of e-commerce transaction intentions across two nations. European Journal of Information Systems, 25(3), 252-273. https://doi.org/10.1057/ ejis.2015.16.

54. Kim, K., \& Kim, J. (2011). Third-party privacy certification as an online advertising strategy: An investigation of the factors affecting the relationship between third-party certification and initial trust. Journal of Interactive Marketing, 25(3), 145-158. https://doi.org/10.1016/j.intma r.2010.09.003.

55. Kimery, K. M., \& McCord, M. (2006). Signals of trustworthiness in e-commerce: Consumer Understanding Of Third-Party Assurance Seals. Journal of Electronic Commerce in Organizations, 4(4), 52-73. https://doi.org/10.4018/jeco.2006100103.

56. Kimery, K. M., \& McCord, M. (2008). Seals on retail web sites. In M. Khosrow-Pour (Ed.), Web Technologies for commerce and services online (pp. 111-134, Advances in Electronic Commerce). Pennsylvania: IGI Global.

57. Krippendorff, K. (2008). Content analysis. Beverly Hills, CA: Sage.

58. Lala, V., Arnold, V., Sutton, S. G., \& Guan, L. (2002). The impact of relative information quality of e-commerce assurance seals on internet purchasing behavior. International Journal of Accounting Information Systems, 3(4), 237-253. https://doi.org/10.1016/S1467-0895(02)00069-6.

59. Langfield-Smith, K. (1992). Exploring the need for a shared cognitive map. Journal of Management Studies, 29(3), 349-368. https://doi.org/10.1111/j.1467-6486.1992.tb00669.x.

60. Lansing, J., Benlian, A., \& Sunyaev, A. (2018). Unblackboxing decision makers' interpretations of IS certifications in the context of cloud service certifications. Journal of the Association for Information Systems, 19, 1064-1096. https://doi.org/10.17705/1jais.00520.

61. Lansing, J., Siegfried, N., Sunyaev, A., \& Benlian, A. (2019). Strategic signaling through cloud service certifications. The Journal of Strategic Information Systems, 28(4), 1-23. https://doi. org/10.1016/j.jsis.2019.101579.

62. Lee, M. K. O., \& Turban, E. (2001). A trust model for consumer internet shopping. International Journal of Electronic Commerce, 6(1), 75-91. https://doi.org/10.1080/10864415.2001.11044227.

63. Lee, P.-M. (2002). Behavioral model of online purchasers in e-commerce environment. Electronic Commerce Research, 2(1/2), 75-85. https://doi.org/10.1023/A\%3A1013340118965.

64. Limayem, M., \& Hirt, S. G. (2003). Force of habit and information systems usage: Theory and initial validation. Journal of the Association for Information Systems, 4(1), 65-97. https://doi. org/10.17705/1jais.00030.

65. Lins, S., Schneider, S., \& Sunyaev, A. (2018). Trust is good, control is better: Creating secure clouds by continuous auditing. IEEE Transactions on Cloud Computing. https://doi.org/10.1109/ TCC.2016.2522411.

66. Lins, S., Schneider, S., Szefer, J., Ibraheem, S., \& Ali, A. (2019). Designing monitoring systems for continuous certification of cloud services: Deriving meta-requirements and design guidelines. Communications of the Association for Information Systems. https://doi.org/10.17705/1CAIS .04425 .

67. Lins, S., \& Sunyaev, A. (2017). Unblackboxing IT certifications: A theoretical model explaining IT certification effectiveness. In Proceedings of the 38th international conference on information systems (ICIS 2017), Seoul, South Korea, 10-13 December 2017 (pp. 1-13).

68. Linstone, H. A., \& Turoff, M. (1975). The Delphi method: Techniques and applications (1st ed.). MA: Addison-Wesley Reading.

69. Llopis, J., \& José Tarí, J. (2003). The importance of internal aspects in quality improvement. International Journal of Quality \& Reliability Management, 20(3), 304-324. https://doi. org/10.1108/02656710310461314.

70. Löbbers, J., \& Benlian, A. (2019). The effectiveness of IS certification in E-commerce: Does personality matter? Journal of Decision Systems, 28(3), 233-259. https://doi.org/10.1080/12460 125.2019.1684867.

71. Löbbers, J., \& Siegfried, N. (2018). Toward a unified view of IS certification: A structured literature review on theoretical lenses. In Proceedings of the 26th European conference on information systems (ECIS 2018), Portsmouth, UK, 23-28 June 2018 (pp. 1-20).

72. Los Angeles Times. (2014). Regulators say web privacy firm TRUSTe deceived consumers. https:// www.latimes.com/business/la-fi-truste-fine-20141117-story.html. Accessed 8 May 2020.

73. Lowry, P. B., Moody, G., Vance, A., Jensen, M., Jenkins, J., \& Wells, T. (2012). Using an elaboration likelihood approach to better understand the persuasiveness of website privacy assurance cues 
for online consumers. Journal of the American Society for Information Science and Technology, 63(4), 755-776. https://doi.org/10.1002/asi.21705.

74. Lynn, T., van der Werff, L., Hunt, G., \& Healy, P. (2016). Development of a cloud trust label: A Delphi approach. Journal of Computer Information Systems, 56(3), 185-193. https://doi. org/10.1080/08874417.2016.1153887.

75. MacCarthy, B. L., \& Atthirawong, W. (2003). Factors affecting location decisions in international operations: A Delphi study. International Journal of Operations \& Production Management, 23(7), 794-818. https://doi.org/10.1108/01443570310481568.

76. Mandle, N. K. (2009). Shopping online? Be wary of web seals and user reviews. https://www. consumerreports.org/cro/news/2009/11/shopping-online-be-wary-of-web-seals-and-user-reviews/ index.htm. Accessed 8 May 2020.

77. Marimon, F., \& Casadesús, M. (2017). Reasons to adopt ISO 50001 energy management system. Sustainability, 9(10), 1740. https://doi.org/10.3390/su9101740.

78. Marin, R. S. (1991). Apathy: A neuropsychiatric syndrome. The Journal of neuropsychiatry and clinical neurosciences, 3(3), 243-254. https://doi.org/10.1176/jnp.3.3.243.

79. Martínez-Costa, M., Martínez-Lorente, A. R., \& Choi, T. Y. (2008). Simultaneous consideration of TQM and ISO 9000 on performance and motivation. International Journal of Production Economics, 113(1), 23-39. https://doi.org/10.1016/j.ijpe.2007.02.046.

80. Mauldin, E., \& Arunachalam, V. (2002). An experimental examination of alternative forms of web assurance for business-to-consumer e-commerce. Journal of Information Systems, 16(1), 33-54. https://doi.org/10.2308/jis.2002.16.s-1.33.

81. Mavlanova, T., Benbunan-Fich, R., \& Lang, G. (2016). The role of external and internal signals in e-commerce. Decision Support Systems, 87, 59-68. https://doi.org/10.1016/j.dss.2016.04.009.

82. McCoy, S., Everard, A., \& Loiacono, E. T. (2009). Online ads in familiar and unfamiliar sites: Effects on perceived website quality and intention to reuse. Information Systems Journal, 19(4), 437-458. https://doi.org/10.1111/j.1365-2575.2007.00290.x.

83. McKnight, D. H., Kacmar, C. J., \& Choudhury, V. (2004). Shifting factors and the ineffectiveness of third party assurance seals: A two-stage model of initial trust in a web business. Electronic Markets, 14(3), 252-266. https://doi.org/10.1080/1019678042000245263.

84. McKnight, H. D., Choudhury, V., \& Kacmar, C. (2002). The impact of initial consumer trust on intentions to transact with a web site: A trust building model. The Journal of Strategic Information Systems, 11(3-4), 297-323. https://doi.org/10.1016/S0963-8687(02)00020-3.

85. Milne, G. R., \& Culnan, M. J. (2004). Strategies for reducing online privacy risks: Why consumers read (or don't read) online privacy notices. Journal of Interactive Marketing, 18(3), 15-29. https:// doi.org/10.1002/dir.20009.

86. Moores, T. (2005). Do consumers understand the role of privacy seals in e-commerce? Communications of the ACM, 48(3), 86-91. https://doi.org/10.1145/1047671.1047674.

87. Mousavizadeh, M., Kim, D. J., \& Chen, R. (2016). Effects of assurance mechanisms and consumer concerns on online purchase decisions: An empirical study. Decision Support Systems, 92, 79-90. https://doi.org/10.1016/j.dss.2016.09.011.

88. Murphy, M. K., Black, N. A., Lamping, D. L., McKee, C. M., Sanderson, C. F. B., Askham, J., et al. (1998). Consensus development methods, and their use in clinical guideline development. Health Technology Assessment, 2(3), 1-88.

89. Nair, A., \& Prajogo, D. (2009). Internalisation of ISO 9000 standards: the antecedent role of functionalist and institutionalist drivers and performance implications. International Journal of Production Research, 47(16), 4545-4568. https://doi.org/10.1080/00207540701871069.

90. Neuendorf, K. A. (2002). The content analysis guidebook. Los Angeles, CA: Sage.

91. Nöteberg, A., Christiaanse, E., \& Wallage, P. (2003). Consumer trust in electronic channels: The impact of electronic commerce assurance on consumers' purchasing likelihood and risk perceptions. E-service Journal, 2(2), 46-67. https://doi.org/10.2979/esj.2003.2.2.46.

92. Obermiller, C., \& Spangenberg, E. R. (1998). Development of a scale to measure consumer skepticism toward advertising. Journal of Consumer Psychology, 7(2), 159-186. https://doi.org/10.1207/ s15327663jcp0702_03.

93. Odom, M. D., Kumar, A., \& Saunders, L. (2002). Web assurance seals: How and why they influence consumers' decisions. Journal of Information Systems, 16(2), 231-250. https://doi. org/10.2308/jis.2002.16.2.231.

94. Ogbanufe, O., Dinulescu, C. C., Liu, X., \& Kucuk, C. Y. (2019). It's in the Cloud. ACM SIGMIS Database, 50(3), 116-137. https://doi.org/10.1145/3353401.3353408. 
95. Okoli, C., \& Pawlowski, S. D. (2004). The Delphi method as a research tool: An example, design considerations and applications. Information \& Management, 42(1), 15-29. https://doi. org/10.1016/j.im.2003.11.002.

96. Özpolat, K., Gao, G., Jank, W., \& Viswanathan, S. (2013). The value of third-party assurance seals in online retailing: An empirical investigation. Information Systems Research, 24(4), 1100-1111. https://doi.org/10.1287/isre.2013.0489.

97. Paré, G., Cameron, A.-F., Poba-Nzaou, P., \& Templier, M. (2013). A systematic assessment of rigor in information systems ranking-type Delphi studies. Information \& Management, 50(5), 207217. https://doi.org/10.1016/j.im.2013.03.003.

98. Pavlou, P. A., \& Gefen, D. (2004). Building effective online marketplaces with institution-based trust. Information Systems Research, 15(1), 37-59.

99. Perkins, S. J., \& Hendry, C. (2005). Ordering top pay: Interpreting the signals. Journal of Management Studies, 42(7), 1443-1468. https://doi.org/10.1111/j.1467-6486.2005.00550.x.

100. Piccinini, E., Hanelt, A., Gregory, R., \& Kolbe, L. (2015). Transforming industrial business: The impact of digital transformation on automotive organizations. In Proceedings of the international conference on information systems (ICIS 2015), Fort Worth, TX, USA, 13-16 December 2015, 2015 (pp. 1-20).

101. Ponte, E. B., Carvajal-Trujillo, E., \& Escobar-Rodríguez, T. (2015). Influence of trust and perceived value on the intention to purchase travel online: Integrating the effects of assurance on trust antecedents. Tourism Management, 47, 286-302. https://doi.org/10.1016/j.tourman.2014.10.009.

102. Prajogo, D., Tang, A. K. Y., \& Lai, K.-H. (2012). Do firms get what they want from ISO 14001 adoption? An Australian perspective. Journal of Cleaner Production, 33, 117-126. https://doi. org/10.1016/j.jclepro.2012.04.019.

103. Prajogo, D. I. (2011). The roles of firms' motives in affecting the outcomes of ISO 9000 adoption. International Journal of Operations \& Production Management, 31(1), 78-100. https://doi. org/10.1108/01443571111098753.

104. Rao, A. R., Qu, L., \& Ruekert, R. W. (1999). Signaling unobservable product quality through a brand ally. Journal of Marketing Research, 36(2), 258. https://doi.org/10.2307/3152097.

105. Rifon, N. J., Larose, R., \& Choi, S. (2005). Your privacy is sealed: Effects of web privacy seals on trust and personal disclosures. Journal of Consumer Affairs, 39(2), 339-362. https://doi.org/ 10.1111/j.1745-6606.2005.00018.x.

106. Rodrigues, R., Wright, D., \& Wadhwa, K. (2013). Developing a privacy seal scheme (that works). International Data Privacy Law, 3(2), 100-116. https://doi.org/10.1093/idpl/ips037.

107. Rohrbaugh, J. (1979). Improving the quality of group judgment: Social judgment analysis and the Delphi Technique. Organizational Behavior and Human Performance, 24(1), 73-92. https:// doi.org/10.1016/0030-5073(79)90017-5.

108. Sampaio, P., Saraiva, P., \& Guimarães Rodrigues, A. (2010). A classification model for prediction of certification motivations from the contents of ISO 9001 audit reports. Total Quality Management \& Business Excellence, 21(12), 1279-1298. https://doi.org/10.1080/14783 363.2010.529367.

109. Schmidt, R., Lyytinen, K., Keil, M., \& Cule, P. (2001). Identifying software project risks: An international Delphi study. Journal of Management Information Systems, 17(4), 5-36. https:// doi.org/10.1080/07421222.2001.11045662.

110. Schmidt, R. C. (1997). Managing Delphi surveys using nonparametric statistical techniques. Decision Sciences, 28(3), 763-774. https://doi.org/10.1111/j.1540-5915.1997.tb01330.x.

111. Schneider, S., Lansing, J., Gao, F., \& Sunyaev, A. (2014). A taxonomic perspective on certification schemes: development of a taxonomy for cloud service certification criteria. In Proceedings of the 47th Hawaii international conference on system sciences (HICSS), Waikoloa, HI, USA, 6-9 January 2014 (pp. 4998-5007). 10.1109/HICSS.2014.614.

112. Shaw, M. L. G., \& Gaines, B. R. (1989). Comparing conceptual structures: Consensus, conflict, correspondence and contrast. Knowledge Acquisition, 1(4), 341-363. https://doi.org/10.1016/ S1042-8143(89)80010-X.

113. Singh, R., Keil, M., \& Kasi, V. (2009). Identifying and overcoming the challenges of implementing a project management office. European Journal of Information Systems, 18(5), 409427. https://doi.org/10.1057/ejis.2009.29.

114. Spence, M. (2002). Signaling in retrospect and the informational structure of markets. American Economic Review, 92(3), 434-459. https://doi.org/10.1257/00028280260136200. 
115. Statista Survey. (2017). Would you generally say that you would have more faith in the reliability of a shop you haven't yet purchased from if it displayed a seal of approval on its website? https://www.statista.com/statistics/705482/faith-in-seal-of-approval-in-the-us/. Accessed 8 May 2020.

116. Statista Survey. (2017). Do you know what seals of approval for online shops are? https://www. statista.com/statistics/705448/awareness-about-seal-of-approval-for-online-shopping-in-the-us/. Accessed 8 May 2020.

117. Sunyaev, A., \& Schneider, S. (2013). Cloud services certification. Communications of ACM, 56(2), 33-36. https://doi.org/10.1145/2408776.2408789.

118. Terlaak, A., \& King, A. A. (2006). The effect of certification with the ISO 9000 Quality Management Standard: A signaling approach. Journal of Economic Behavior and Organization, 60(4), 579-602. https://doi.org/10.1016/j.jebo.2004.09.012.

119. Thiebes, S., Lyytinen, K., \& Sunyaev, A. (2017). Sharing is about caring? Motivating and discouraging factors in sharing individual genomic data. In Proceedings of the 38th international conference on information systems (ICIS 2017), Seoul, South Korea, 10-13 December 2017.

120. Triandis, H. C. (1979). Values, attitudes, and interpersonal behavior. Nebraska Symposium on Motivation, 27, 195-259.

121. TrustedShops. (2020). List of certified shops. Cologne: TrustedShops. https://www.trustedsho ps.eu/finder/. Accessed 8 May 2020.

122. Urquhart, C., Lehmann, H., \& Myers, M. D. (2010). Putting the 'theory' back into grounded theory: Guidelines for grounded theory studies in information systems. Information Systems Journal, 20(4), 357-381. https://doi.org/10.1111/j.1365-2575.2009.00328.x.

123. van Baal, S. (2015). Not all seals are equal: An experimental investigation of the effect of thirdparty seals on purchase probability in electronic commerce. Electronic Commerce Research, 15(2), 177-206. https://doi.org/10.1007/s10660-015-9180-9.

124. Venkatesh, V., Brown, S. A., Maruping, L. M., \& Bala, H. (2008). Predicting different conceptualizations of system use: The competing roles of behavioral intention, facilitating conditions, and behavioral expectation. MIS Quarterly, 32(3), 483. https://doi.org/10.2307/25148853.

125. Venkatesh, V., \& Davis, F. D. (2000). A theoretical extension of the technology acceptance model: Four longitudinal field studies. Management Science, 46(2), 186-204. https://doi. org/10.1287/mnsc.46.2.186.11926.

126. Wakefield, R. L., Stocks, M. H., \& Wilder, W. M. (2004). The role of web site characteristics in initial trust formation. Journal of Computer Information Systems, 45(1), 94-103. https://doi. org/10.1080/08874417.2004.11645821.

127. Wakefield, R. L., \& Whitten, D. (2008). Examining user perceptions of third-party organizations credibility and trust in an e-retailer. In S. Clarke (Ed.), End-user computing: Concepts, methodologies, tools, and applications (pp. 1637-1651). Hershey, PA: IGI Global.

128. Yang, S.-C., Hung, W.-C., Sung, K., \& Farn, C.-K. (2006). Investigating initial trust toward e-tailers from the elaboration likelihood model perspective. Psychology \& Marketing, 23(5), 429-445. https://doi.org/10.1002/mar.20120.

129. Zhou, T. (2015). Understanding user adoption of location-based services from a dual perspective of enablers and inhibitors. Information Systems Frontiers, 17(2), 413-422. https://doi.org/10.1007/ s10796-013-9413-1.

130. Zucker, L. G. (1986). Production of trust: Institutional sources of economic structure. Research in Organizational Behavior, 8, 53-111.

Publisher's Note Springer Nature remains neutral with regard to jurisdictional claims in published maps and institutional affiliations. 